\title{
BMJ Open Investigating correlates of athletic identity and sport-related injury outcomes: a scoping review
}

\author{
Tian Renton (D) , ${ }^{1,2}$ Brian Petersen, ${ }^{3}$ Sidney Kennedy ${ }^{1,2,4}$
}

To cite: Renton T, Petersen B, Kennedy S. Investigating correlates of athletic identity and sport-related injury outcomes: a scoping review. BMJ Open 2021;11:e044199. doi:10.1136/ bmjopen-2020-044199

- Prepublication history for this paper is available online. To view these files, please visit the journal online ().

Received 26 August 2020 Revised 16 January 2021 Accepted 03 March 2021

A) Check for updates

C Author(s) (or their employer(s)) 2021. Re-use permitted under CC BY-NC. No commercial re-use. See rights and permissions. Published by BMJ.

${ }^{1}$ Rehabilitation Sciences Institute, University of Toronto Faculty of Medicine, Toronto,

Ontario, Canada

${ }^{2}$ Centre for Depression and Suicide Studies, St Michael's Hospital, Toronto, Ontario, Canada

${ }^{3}$ Faculty of Kinesiology and Physical Education, University of Toronto, Toronto, Ontario, Canada

${ }^{4}$ Department of Psychiatry, University of Toronto Faculty of Medicine, Toronto, Ontario, Canada

Correspondence to

Tian Renton;

tian.renton@mail.utoronto.ca

\section{ABSTRACT}

Objectives To conduct a scoping review that (1) describes what is known about the relationship between athletic identity and sport-related injury outcomes and (2) describes the relationship that an injury (as an exposure) has on athletic identity (as an outcome) in athletes. Design Scoping review.

Participants A total of $n=1852$ athletes from various sport backgrounds and levels of competition.

Primary and secondary outcome measures The primary measure used within the studies identified was the Athletic Identity Measurement Scale. Secondary outcome measures assessed demographic, psychosocial, behavioural, physical function and pain-related constructs. Results Twenty-two studies were identified for inclusion. Samples were dominated by male, Caucasian athletes. The majority of studies captured musculoskeletal injuries, while only three studies included sport-related concussion. Athletic identity was significantly and positively associated with depressive symptom severity, sport performance traits (eg, ego-orientation and mastery-orientation), social network size, physical self-worth, motivation, rehabilitation overadherence, mental toughness and playing through pain, as well as injury severity and functional recovery outcomes. Findings pertaining to the association that an injury (as an exposure) had on athletic identity (as an outcome) were inconsistent and limited.

Conclusions Athletic identity was most frequently associated with psychosocial, behavioural and injuryspecific outcomes. Future research should seek to include diverse athlete samples (eg, women, athletes of different races, para-athletes) and should continue to reference theoretical injury models to inform study methodologies and to specify variables of interest for further exploration.

\section{INTRODUCTION}

Participation in sport, be it in a formal (eg, registered league) or informal (eg, pick-up, drop-in) setting, is a popular pastime for individuals the world over. Positive benefits associated with sport participation include increased mental toughness, ${ }^{1}$ perseverance ${ }^{12}$ and positive self-esteem, ${ }^{2-4}$ as well as the development of fine and gross motor skills, team work and problem-solving abilities. ${ }^{5}$ These benefits are aside from the countless physical (eg, maintenance of a healthy body weight ${ }^{6}$ ), mental (eg, reduction in depression ${ }^{7}$ and

\section{Strengths and limitations of this study}

The search strategy was constructed in consultation with a University of Toronto librarian.

- Citation management (EndNote) and systematic review citation screening software (Covidence) were used to allow reviewers to independently screen citations and extract data.

- Data extraction variables thoroughly described the study sample, injuries sustained, theoretical models referenced, athletic identity scores and timeline of administration, significant key findings as well as study strengths and limitations.

- A quality assessment was not conducted, and level of evidence ratings were not assigned to studies.

anxiety symptoms ${ }^{8}$ ) and cognitive benefits (eg, improved academic performance ${ }^{9}$ and memory recall ${ }^{10}$ ) associated with physical activity in general. Despite these benefits, negative outcomes should also be considered, namely risk of injury. However, not all athletes are created equal, nor are their respective risks of sport injury. This is illustrated by several large-scale epidemiological studies describing marked differences in injury incidence when stratified by sport. ${ }^{11-16}$ Internal risk factors, such as an athlete's biological and physical characteristics (eg, age, sex, anthropometry, skill level and physical fitness) as well as their psychological predisposition (eg, personality, history of stressors and availability of coping resources) are also posited to modify injury risk. ${ }^{17-19}$ External factors, such as level of competition and playing surface, have also been implicated. ${ }^{18} 19$

Despite individual athlete (eg, physicality, disposition) and sport-specific differences (eg, type, level, frequency of involvement, injury risk), all athletes are thought to embody an 'athletic identity' (AI). Initially defined by Brewer et al in 1993, AI is defined as 'the exclusivity and strength with which an individual identifies with the athlete role, and looks to others for confirmation of that role' ${ }^{20}$ 
To some extent, an athlete's self-perception of their AI can provide an important measure of their longevity in sport. ${ }^{21}$ Stronger AIs have been associated with positive health outcomes, increased sport engagement, enhanced athletic performance, improved global self-esteem and confidence, as well as improved social relationships. ${ }^{2022-25}$ Conversely, following a sport-related injury, stronger AIs have been associated with depressive symptoms. ${ }^{26}$ It has also been suggested that athletes who hold a stronger AI may neglect other identities and role responsibilities to maintain the athlete role. ${ }^{20}$ Therefore, a strong AI may be helpful in some cases and harmful in others, especially within a sport injury context.

Athletes will continue to sustain injuries so long as sport exists, thus illustrating the need to understand factors associated with recovery. To inform stakeholders' (eg, clinicians, coaches, athletes) understanding and expectations, many theoretical injury recovery models have been developed, several of which are presented here: The Biopsychosocial Model ${ }^{27}$; Biopsychosocial Model of Stress and Athletic Injury ${ }^{29}$; Integrated Model of Psychological Response to the Sport Injury and Rehabilitation Process ${ }^{30}$; and Cognitive Appraisal Model of Psychological Adjustment to Athletic Injury. ${ }^{31}$ Although not specific to sport, some models have been developed to explain and predict outcomes associated with a specific injury, such as concussion (Neurobiopsychosocial Model of Concussion $^{32}$ ). Others have been adapted from existing models (Transactional Stress Mode ${ }^{33}$ ) to suit a sport injury context (Injury Response Mode ${ }^{34}{ }^{35}$ ). For a more comprehensive review of select models, please see the following article. ${ }^{36}$ Despite variation in the labelling used within the models cited above, constructs can be categorised as modifiable (ie, flexible, subject to intervention) or non-modifiable (ie, fixed, unchanging). With respect to addressing recovery outcomes, attention is best focused on modifiable factors because they are subject to intervention. Prior to implementing an intervention however, efforts should focus on describing recovery outcomes observed for a given factor. To our knowledge, AI (a modifiable factor) has not been summarised in detail with respect to its association with sport injury recovery outcomes.

To address this knowledge gap and to provide a comprehensive summary of what is known about AI in relation to sport-related injury outcomes, authors conducted a scoping review. To guide this review, the following questions were established a priori:

1. Is there an association between athlete self-reported $\mathrm{AI}$ and response to a sport-related injury? If so, what is known? Response to injury is operationally defined as any outcome observed following injury (eg, psychosocial, behavioural, functional, cognitive or performance).

2. Is there an association between a sport-related injury (as an exposure) and athlete self-reported AI (as an outcome)? If so, what is known?

\section{METHOD}

\section{Search strategy and study identification}

Search strategies and terms were developed in consultation with a University of Toronto health science librarian (EN; 20 January 2020). The following databases were searched in March and April 2020 by one reviewer (TR): MEDLINE, EMBASE, SPORTDiscus, CINAHL, APA PsycInfo, and Sport Medicine \& Education Index (Proquest). The number of citations identified were recorded in table 1.

Search results were exported to EndNote ${ }^{37}$ and duplicates were discarded $(\mathrm{n}=334)$. Thereafter, article titles and abstracts $(\mathrm{n}=1122)$ were exported to Covidence. ${ }^{38}$ Covidence collates each reviewer's decision to accept or reject a citation and identifies screening conflicts for resolution. The programme also populates a Preferred Reporting Items for Systematic Reviews and Meta-Analyses (PRISMA) flow chart to reflect the number of citations included or excluded at each screening stage (see online supplemental appendix 1). Reasons for exclusion were cited at the full-text screening stage only. Studies identified for inclusion at full-text screening also had their reference lists reviewed for additional studies. ClinicalTrials.gov was also searched using the following terms: "athlete", "identity", "injury" and "sport", but did not identify any additional studies. TR and BP independently performed each stage of the screening process (titles, abstracts and fulltext screening) as well as full-text data extraction. After completing each stage, reviewers met virtually (via Zoom) to discuss and resolve conflicts. Progression to the next screening stage occurred only after $100 \%$ agreement was achieved. The same process was applied throughout the data extraction phase. For quality assurance, this scoping review was structured according to the PRISMA extension for scoping reviews checklist (see online supplemental appendix 2).

\section{Study inclusion criteria}

1. AI was assessed using a self-report quantitative measure.

2. Study sample consisted of at least one group with a sport-related injury which prevented them from engaging in sport.

3. Injuries were real or hypothetical (ie, imaginary).

4. Studies captured athletes of any age and playing status (eg, amateur or professional, retired or active). Studies that included athletes with disabilities (eg, paraathletes) were permissible, however, the injury must have been secondary to the existing disability (ie, study must pertain to a sport-related injury).

5. An objective measure was used to assess the injury or post-rehabilitation status or post-injury AI.

\section{Study exclusion criteria}

1. Article not available in the English language.

2. Full-text article could not be located following direct request to author(s) (if not available online).

3. Injury was not specified or assessed for severity. 
Table 1 Search strategies by database

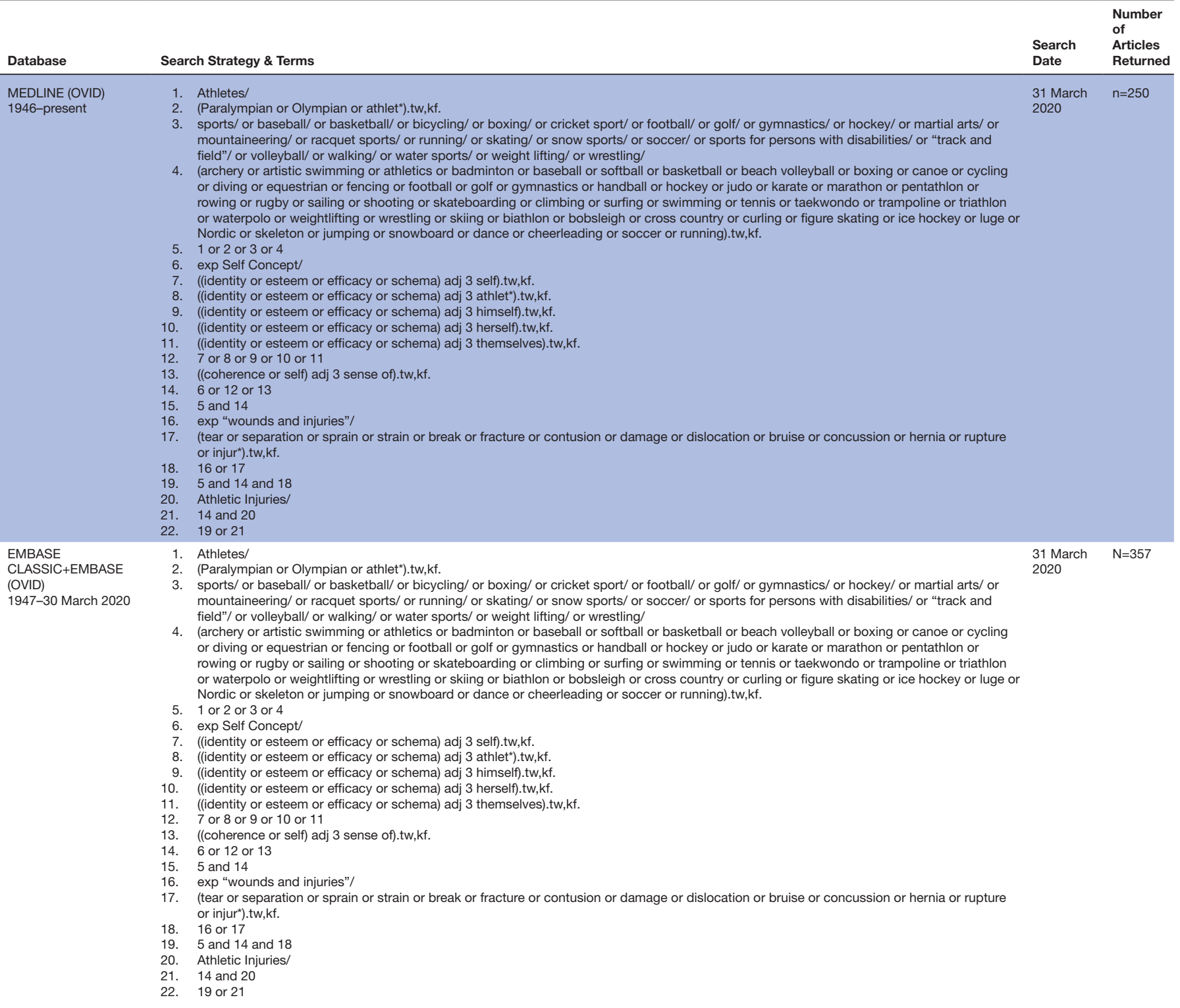

Continued 
Table 1 Continued athletes" OR DE "BOBSLEDDERS" OR DE "BODYBUILDERS" OR DE "BOWLERS" OR DE "BOXERS (Sports)" OR DE "BULLFIGHTERS" OR DE "CANADIAN athletes" OR DE "CANOEISTS" OR DE "CELEBRITY athletes" OR DE "CHILD athletes" OR DE "CHILDREN of athletes" OR DE "CHRISTIAN athletes" OR DE "COLLEGE athletes" OR DE "CRICKET players" OR DE "CROQUET players" OR DE "CURLERS (Athletes)" OR DE "CYCLISTS" OR DE "DEFENSIVE players" OR DE "DIABETIC athletes" OR DE "ELITE athletes" OR DE "ENDURANCE athletes" OR DE OR DE "CYCLISTS" OR DE "DEFENSIVE players" OR DE "DIABETIC athletes" OR DE "ELITE athletes" OR DE "ENDURANCE athletes" OR DE
"EUROPEAN athletes" OR DE "FENCERS" OR DE "FOOTBALL players" OR DE "GAY athletes" OR DE "GLADIATORS" OR DE "GOLFERS" OR "EUROPEAN athletes" OR DE "FENCERS" OR DE "FOOTBALL players" OR DE "GAY athletes" OR DE "GLADIATORS" OR DE "GOLFERS" OR
DE "GYMNASTS" OR DE "HANDBALL players" OR DE "HIGH school athletes" OR DE "HOCKEY players" OR DE "INTERSEX athletes" OR DE "JAI alai players" OR DE "JEWISH athletes" OR DE "JUNIOR high school athletes" OR DE "KABADDI players" OR DE "LACROSSE players" OR DE "LAWN bowlers" OR DE "LGBTQ athletes" OR DE "LONG-term athlete development" OR DE "MALE athletes" OR DE "MARTIAL artists" OR DE "MEXICAN athletes" OR DE "MIDDLE school athletes" OR DE "MOUNTAINEERS" OR DE "MUSLIM athletes" OR DE "NATIVE American athletes" OR DE "NETBALL players" OR DE "OFFENSIVE players" OR DE "OLDER athletes" OR DE "OLYMPIC athletes" OR DE "ORIENTEERS" OR DE "PACIFIC Islander athletes" OR DE "PROFESSIONAL athletes" OR DE "ROWERS" OR DE "RUGBY football players" OR DE "RUNNERS (Sports)" OR DE "SKATERS" OR DE "SKIERS" OR DE "SKYDIVERS" OR DE "SNOWBOARDERS" OR DE "SOCCER players" OR DE "SOFTBAL players" OR DE "SQUASH players" OR DE "STARTING players" OR DE "SUBSTITUTE players" OR DE "SURFERS" OR DE "SWIMMERS" OR DE "TABLE tennis players" OR DE "TEAM handball players" OR DE "TENNIS players" OR DE "TRACK \& field athletes" OR DE "TRIATHLETES" OR DE "TABLE tennis players" OR DE "TEAM handball players" OR DE "TENNIS players" OR DE "TRACK \& field athletes" OR DE "TRIATHLETES" OR DE "VOLLEYBALL play"

S2. AB (Paralympian or Olympian or athlet*) OR TI (Paralympian or Olympian or athlet*) OR SU (Paralympian or Olympian or athlet*) OR KW (Paralympian or Olympian or athlet*)

S3. DE "RECREATION" OR DE "AMATEUR sports" OR DE "AQUATIC sports" OR DE "BALL games" OR DE "BASEBALL" OR DE "COLLEGE sports" OR DE "CONTACT sports" OR DE "ENDURANCE sports" OR DE "EXTREME sports" OR DE "GYMNASTICS" OR DE "HOCKEY" OR DE "INDIVIDUAL sports" OR DE "MILITARY sports" OR DE "OLYMPIC Games" OR DE "PROFESSIONAL sports" OR DE "RECREATIONAL sports" OR $\mathrm{DE}$

"SCHOOL sports" OR DE "SOFTBALL" OR DE "SPORTS competitions" OR DE "SPORTS for children" OR DE "SPORTS for girls" OR DE "SPORTS for people with disabilities" OR DE "SPORTS for youth" OR DE "SPORTS teams" OR DE "TARGETS (Sports)" OR DE "TEAM sports" OR DE "WINTER sports" OR DE "WOMEN'S sports"

S4. TI (archery or artistic swimming or athletics or badminton or baseball or softball or basketball or beach volleyball or boxing or canoe or cycling or diving or equestrian or fencing or football or golf or gymnastics or handball or hockey or judo or karate or marathon or pentathlon or rowing or rugby or sailing or shooting or skateboarding or climbing or surfing or swimming or tennis or taekwondo or trampoline or triathlon or waterpolo or weightlifting or wrestling or skiing or biathlon or bobsleigh or cross country or curling or figure skating or ice hockey or luge or Nordic or skeleton or jumping or snowboard or dance or cheerleading or soccer or running) OR AB (archery or artistic swimming or athletics or badminton or baseball or softball or basketball or beach volleyball or boxing or canoe or cycling or diving or equestrian or fencing or football or golf or gymnastics or handball or hockey or judo or karate or marathon or pentathlon or rowing or rugby or sailing or shooting or skateboarding or climbing or surfing or swimming or tennis or taekwondo or trampoline or triathlon or waterpolo or weightlifting or wrestling or skiing or biathlon or bobsleigh or cross country or cr tennis or taekwondo or trampoline or triathlon or waterpolo or weightlifting or wrestling or skiling or biathlon or bobsleigh or cross country or SUrling or figure skating or ice hockey or luge or Nordic or skeleton or jumping or snowboard or dance or cheerleading or soccer or running) OR SU (archery or artistic swimming or athletics or badminton or baseball or softball or basketball or beach volleyball or boxing or canoe or cycling or diving or equestrian or fencing or football or golf or gymnastics or handball or hockey or judo or karate or marathon or pentathlon or rowing or weightlifting or wrestling or skiing or biathlon or bobsleigh or cross country or curling or figure skating or ice hockey or luge or Nordic or skeleton or jumping or snowboard or dance or cheerleading or soccer or running) OR KW (archery or artistic swimming or athletics or badminton or baseball or softball or basketball or beach volleyball or boxing or canoe or cycling or diving or equestrian or fencing or football or golf or gymnastics or handball or hockey or judo or karate or marathon or pentathlon or rowing or rugby or sailing or shooting or skateboarding or climbing or surfing or swimming or tennis or taekwondo or trampoline or triathlon or waterpolo or weightlifting or wrestling or skiing or biathlon or bobsleigh or cross country or or tennis or taekwondo or trampoline or triathlon or waterpolo or weightlifting or wrestling or skiing or biathlon or bobsleigh or cross country
curling or figure skating or ice hockey or luge or Nordic or skeleton or jumping or snowboard or dance or cheerleading or soccer or running) curling or figure skating or ice S6. S1 "SELF-perception" OR DE "BODY image" OR DE "SELF-esteem" S6. DE "SELF-perception" OR DE "BODY image" OR DE "SELF-esteem" people -- Identity" OR DE "PSYCHOLOGY of athletes" OR DE "ATHLETIC identity (Psychology)"

S8. TI ((identity or esteem or efficacy or schema) N3 self) OR AB ((identity or esteem or efficacy or schema) N3 self) OR SU ((identity or esteem or efficacy or schema) N3 self) OR KW ((identity or esteem or efficacy or schema) N3 self)

S9. TI ((identity or esteem or efficacy or schema) N3 athlet*) OR AB ((identity or esteem or efficacy or schema) N3 athlet*) or SU ((identity or esteem or efficacy or schema) N3 athlet*) or KW ((identity or esteem or efficacy or schema) N3 athlet*)

S10. TI ((identity or esteem or efficacy or schema) N3 himself) OR AB ((identity or esteem or efficacy or schema) N3 himself) OR SU ((identity or S10. TI ((identity or esteem or efficacy or schema) N3 himself) OR AB ((identity or esteem or efficacy or

S11. TI ((identity or esteem or efficacy or schema) N3 herself) OR AB ((identity or esteem or efficacy or schema) N3 herself) OR SU ((identity or esteem or efficacy or schema) N3 herself) OR KW ((identity or esteem or efficacy or schema) N3 herself)

S12. TI ((identity or esteem or efficacy or schema) N3 themselves) OR AB ((identity or esteem or efficacy or schema) N3 themselves) OR SU ((identity or esteem or efficacy or schema) N3 themselves) OR KW ((identity or esteem or efficacy or schema) N3 themselves)

S13. S6 OR S7 OR S8 OR S9 OR S10 OR S11 OR S12

S14. TI ((coherence or self) N3 sense of) OR AB ((coherence or self) N3 sense of) OR SU ((coherence or self) N3 sense of) OR KW ((coherence or self) N3 sense of)

S15. S13 OR S14

S16. S5 AND S15

S17. (DE "SPORTS injuries" OR DE "ACHILLES tendinitis" OR DE "AEROBICS injuries" OR DE "AQUATIC sports injuries" OR DE "BASEBALL injuries" OR DE "BASKETBALL injuries" OR DE "BOXING injuries" OR DE "COMMOTIO cordis" OR DE "CRICKET injuries" OR DE "EQUESTRIAN accidents" OR DE "FOOTBALL injuries" OR DE "GOLF injuries" OR DE "GYMNASTICS injuries" OR DE "HIKING injuries" OR DE "HOCKEY injuries" OR DE "HORSE sports injuries" OR DE "IN-line skating injuries" OR DE "JOGGING injuries" OR DE "JUDO injuries" OR DE "JUMPER'S knee" OR DE "KARATE injuries" OR DE "MARTIAL arts injuries" OR DE "NETBALL injuries" OR DE "RACKET game injuries" OR DE "RUGBY football injuries" OR DE "RUNNING injuries" OR DE "SKATEBOARDING injuries" OR DE "SOCCER injuries" OR DE "TENNIS injuries" OR DE "TURF toe" OR DE "VAULTING injuries" OR DE "VOLLEYBALL injuries" OR DE "WALKING (Sports) injuries" OR DE "WEIGHT training injuries" OR DE "WINTER sports injuries") AND (DE "SPORTS injuries" OR DE "SPORTS emergencies" OR DE "SPORTS injuries" OR DE "SPORTS ophthalmology" OR DE "WOUNDS \& injuries" OR DE "BACKPACKING injuries" OR DE "BLUNT trauma" OR DE "CHRONIC wounds \& injuries" OR DE "CRASH injuries" OR DE "DANCING injuries" OR DE "DECOMPRESSION sickness" OR DE "DISABILITIES" OR DE "DISLOCATIONS (Anatomy)" OR DE "HEAD OR DE "DANCING injuries" OR DE "DECOMPRESSION sickness" OR DE "DISABILITIES" OR DE "DISLOCATIONS (Anatomy)" OR DE "HEAD
injuries" OR DE "MARTIAL arts injuries" OR DE "MOUNTAINEERING injuries" OR DE "OVEREXERTION injuries" OR DE "OVERUSE injuries" OR DE injuries" OR DE "MARTIAL arts injuries" OR DE "MOUNTAINEERING injuries" OR DE "OVEREXERTION injuries" OR DE "OVERUSE injuries" OR DE
"PENETRATING wounds" OR DE "PHYSIOLOGIC strain" OR DE "RUPTURE of organs, tissues, etc." OR DE "SOFT tissue injuries" OR DE "SPORTS injuries" OR DE "SUBLUXATION" OR DE "WOUND care")

S18 TI (tear or separation or sprain or strain or break or fracture or contusion or damage or dislocation or bruise or concussion or hernia or rupture or injur*) OR AB (tear or separation or sprain or strain or break or fracture or contusion or damage or dislocation or bruise or concussion or hernia or rupture or injur*) OR SU (tear or separation or sprain or strain or break or fracture or contusion or damage or dislocation or bruise or concussion or hernia or rupture or injur*) OR KW (tear or separation or sprain or strain or break or fracture or contusion or damage or dislocation or bruise or concussion or hernia or rupture or injur*)

S19. S17 OR S18

S19. S17 OR S18

*Use of Thesaurus Function to find DE Terms

Continued 
Table 1 Continued

S1. (MH "Athletes, Amateur") OR (MH"Athletes, College") OR (MH "Athletes, Disabled") OR (MH "Athletes, Elite") OR (MH "Athletes, Female") OR (MH "Athletes, High School") OR (MH "Athletes, Male") OR (MH "Athletes, Master") OR (MH "Athletes, Professional") OR (MH "Athletes")

S4. TI (archery or artistic swimming or athletics or badminton or baseball or softball or basketball or beach volleyball or boxing or canoe or cycling or diving or equestrian or fencing or football or golf or gymnastics or handball or hockey or judo or karate or marathon or pentathlon or rowing or rugby or sailing or shooting or skateboarding or climbing or surfing or swimming or tennis or taekwondo or trampoline or triathlon or waterpolo or weightlifting or wrestling or skiing or biathlon or bobsleigh or cross country or curling or figure skating or ice hockey or luge or Nordic or skeleton or jumping or snowboard or dance or cheerleading or soccer or running) OR AB (archery or artistic swimming or athletics or badminton or baseball or softball or basketball or beach volleyball or boxing or canoe or cycling or diving or equestrian or fencing or football or golf or gymnastics or handball or hockey or judo or karate or marathon or pentathlon or rowing or rugby or sailing or shooting or skateboarding or climbing or surfing or swimming or tennis or taekwondo or trampoline or triathlon or waterpolo or weightlifting or wrestling or skiing or biathlon or bobsleigh or cross country or curling or figure skating or ice hockey or luge or Nordic or skeleton or jumping or snowboard or dance or cheerleading or soccer or running) S5. S1 OR S2 OR S3 OR S4

S6. (MH "Self Concept+")

S7. (MM "Professional Identity") OR (MM "Social Identity") OR (MM "Role")

S8. TI ((identity or esteem or efficacy or schema) N3 self) OR AB ((identity or esteem or efficacy or schema) N3 self)

S9. TI ((identity or esteem or efficacy or schema) N3 athlet*) OR AB ((identity or esteem or efficacy or schema) N3 athlet ${ }^{*}$ )

S10. TI ((identity or esteem or efficacy or schema) N3 himself) OR AB ((identity or esteem or efficacy or schema) N3 himself)

S11. TI ((identity or esteem or efficacy or schema) N3 herself) OR AB ((identity or esteem or efficacy or schema) N3 herself)

S12. TI ((identity or esteem or efficacy or schema) N3 themselves) OR AB ((identity or esteem or efficacy or schema) N3 themselves)

S13. S6 OR S7 OR S8 OR S9 OR S10 OR S11 OR S12

S14. TI ((coherence or self) N3 sense of) OR AB ((coherence or self) N3 sense of)

S15. S13 OR S14

S16. S5 AND S15

S17. (MH "Athletic Injuries+") OR (MM "Contusions and Abrasions") OR (MM "Back Injuries") OR (MM "Fractures") OR (MH "Head Injuries") OR (MH "Leg Injuries") OR (MH "Ligament Injuries") OR (MM “Dislocations") OR (MM "Neck Injuries") OR (MM "Rupture") OR (MM "Soft Tissue Injuries") OR (MM "Spinal Cord Injuries") OR (MM "Spinal Injuries") OR (MM "Sprains and Strains") OR (MM "Tears and Lacerations") OR (MM "Tendon Injuries") OR (MM "Wounds,

Penetrating") OR (MM "Wounds, Nonpenetrating") OR (MM "Subluxation") OR (MM "Reinjury")

S18. TI (tear or separation or sprain or strain or break or fracture or contusion or damage or dislocation or bruise or concussion or hernia or rupture or injur*) OR AU (tear or separation or sprain or strain or break or fracture or contusion or damage or dislocation or bruise or concussion or hernia or rupture or injur*)

rupture or injur)

S19. S17 OR S18

S20. ST6 AND S19

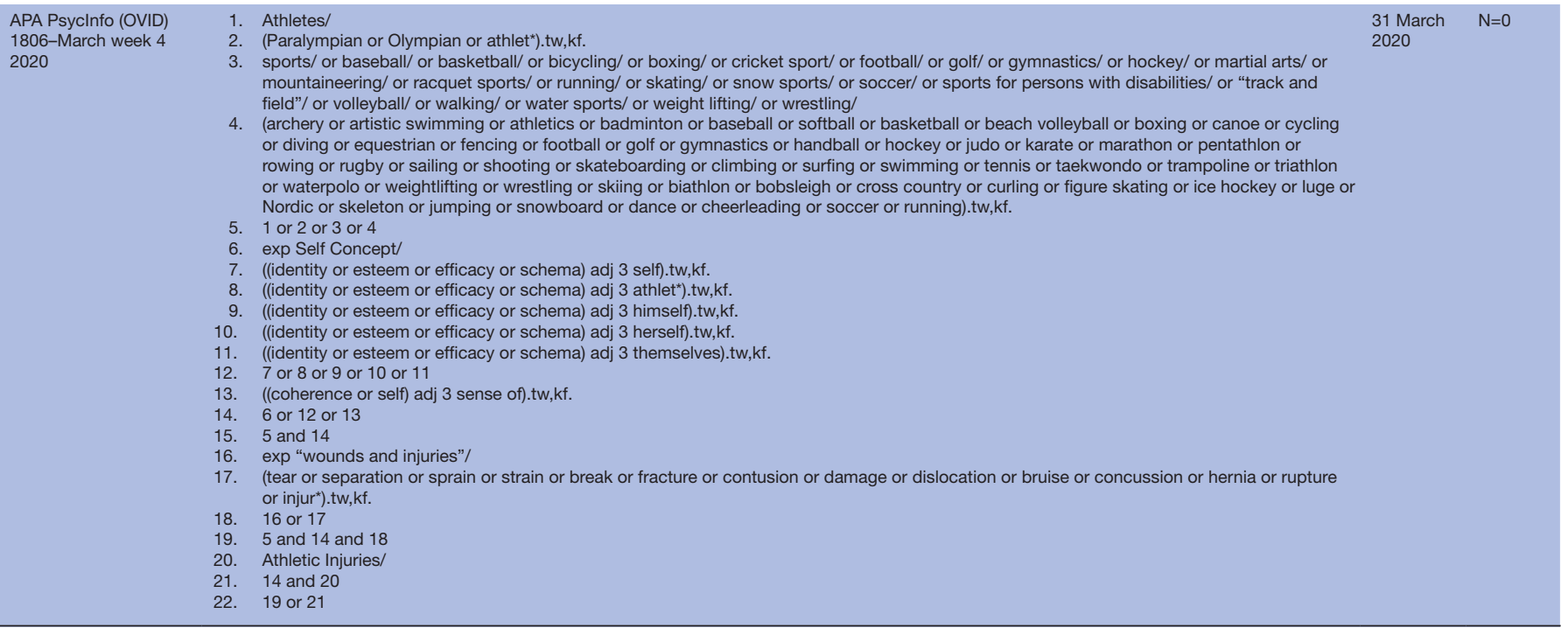

Continued 


\begin{tabular}{|c|c|c|c|}
\hline Database & Search Strategy \& Terms & $\begin{array}{l}\text { Search } \\
\text { Date }\end{array}$ & $\begin{array}{l}\text { Articles } \\
\text { Returned }\end{array}$ \\
\hline $\begin{array}{l}\text { Sport Medicine \& } \\
\text { Education Index } \\
\text { (ProQuest) } \\
\text { 1970-current }\end{array}$ & 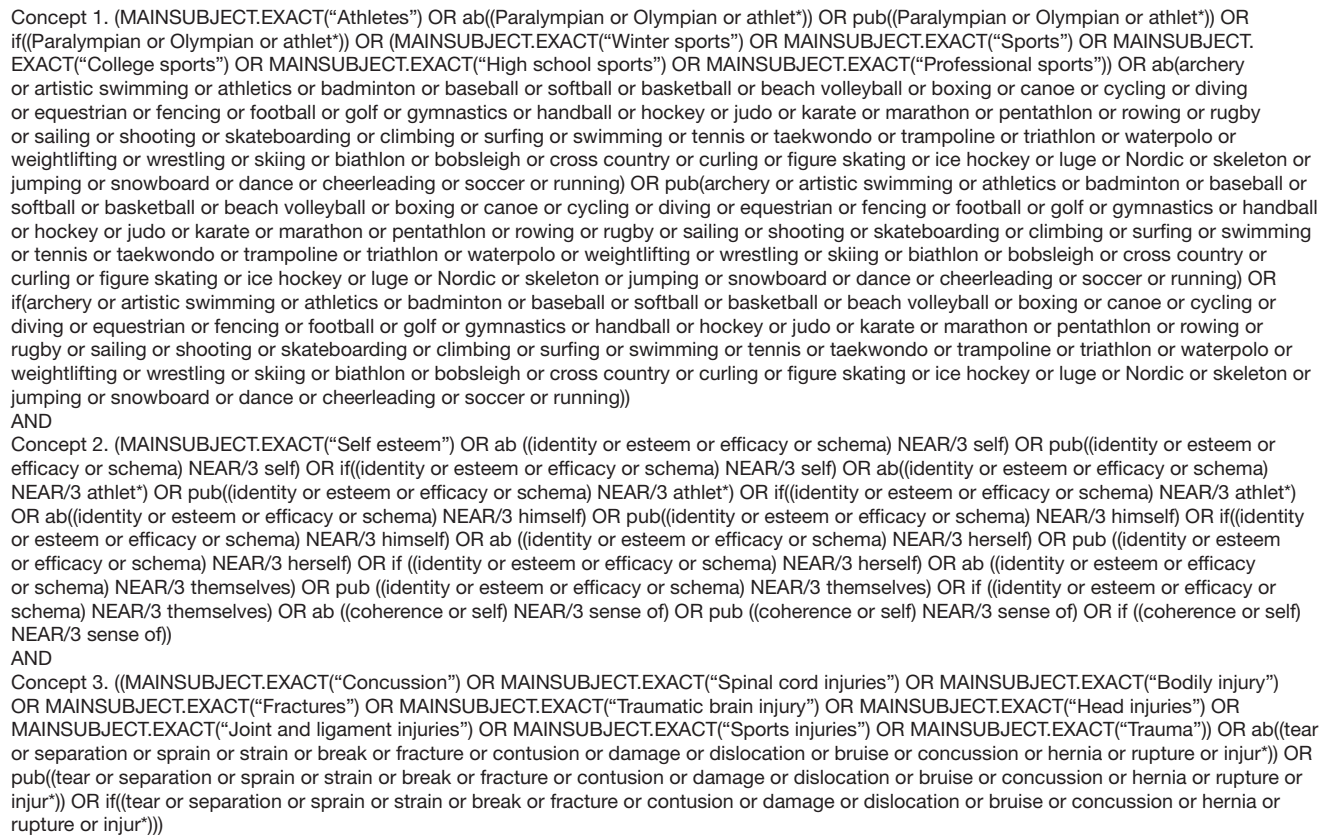 & 2 April 2020 & $N=168$ \\
\hline
\end{tabular}

Total records identified: $n=1456$

4. AI was not self-reported (ie, was reported by a coach, teammate or parent).

5. Conference proceedings or abstracts.

6. Qualitative studies.

7. Systematic, scoping or narrative reviews.

8. Theses or dissertations.

9. Consensus statements.

\section{Data extraction}

The following data were extracted from each of the included studies and logged independently by reviewers into a blank, preformatted table (see table 2 for template).

1. Description of sample: country of origin, sample size, sex, race, age, recruitment source, sport background, level of sport and history of sport involvement (eg, frequency and years of participation).

2. Injury descriptors: definition of injury used (if any), type and severity of injury, time removed from sport, rehabilitation protocol administered and surgical details (if any).

3. Study methodology: study design, primary and secondary objectives.

4. Theoretical support: author and model or theory used.

5. Outcome measures: AI measured used, timeline of administration, AI score and additional outcome measures used.

6. Key findings: findings related to AI and other measured variables.

7. Study strengths and limitations.
Findings are presented as a narrative summary, and where possible, presented as a tally (ie, number of studies that reported on a given finding) to denote trends in the literature. In keeping with the purpose of scoping review methodology which is '...to identify knowledge gaps, scope a body of literature, clarify concepts or to investigate research conduct ${ }^{39}$ as well as '... to identify strengths [and] weaknesses ... in the research', ${ }^{40}$ studies will not undergo quality review (ie, assessment of bias) or be assigned a Level of Evidence rating.

\section{Patient and public involvement}

No patient(s) involved.

\section{RESULTS}

The search strategy identified 1456 records for consideration (see table 1 for databases searched, search terms used and number of records identified). Two additional articles were identified via hand searching of the included article reference lists. One additional article was previously known to others, but not identified in the searches. Two articles contained multiple studies. A total of 20 publications reporting on 22 studies were eligible for inclusion. Studies used cross-section observational $(n=8)$, prospective longitudinal $(\mathrm{n}=13)$ and mixed-methods $(\mathrm{n}=1)$ designs.

\section{Sample descriptors}

Studies originated from Australia $(n=1)$, Canada $(n=1)$, Israel $(n=1)$, Slovenia $(n=1)$ and the USA $(n=18)$. Most 


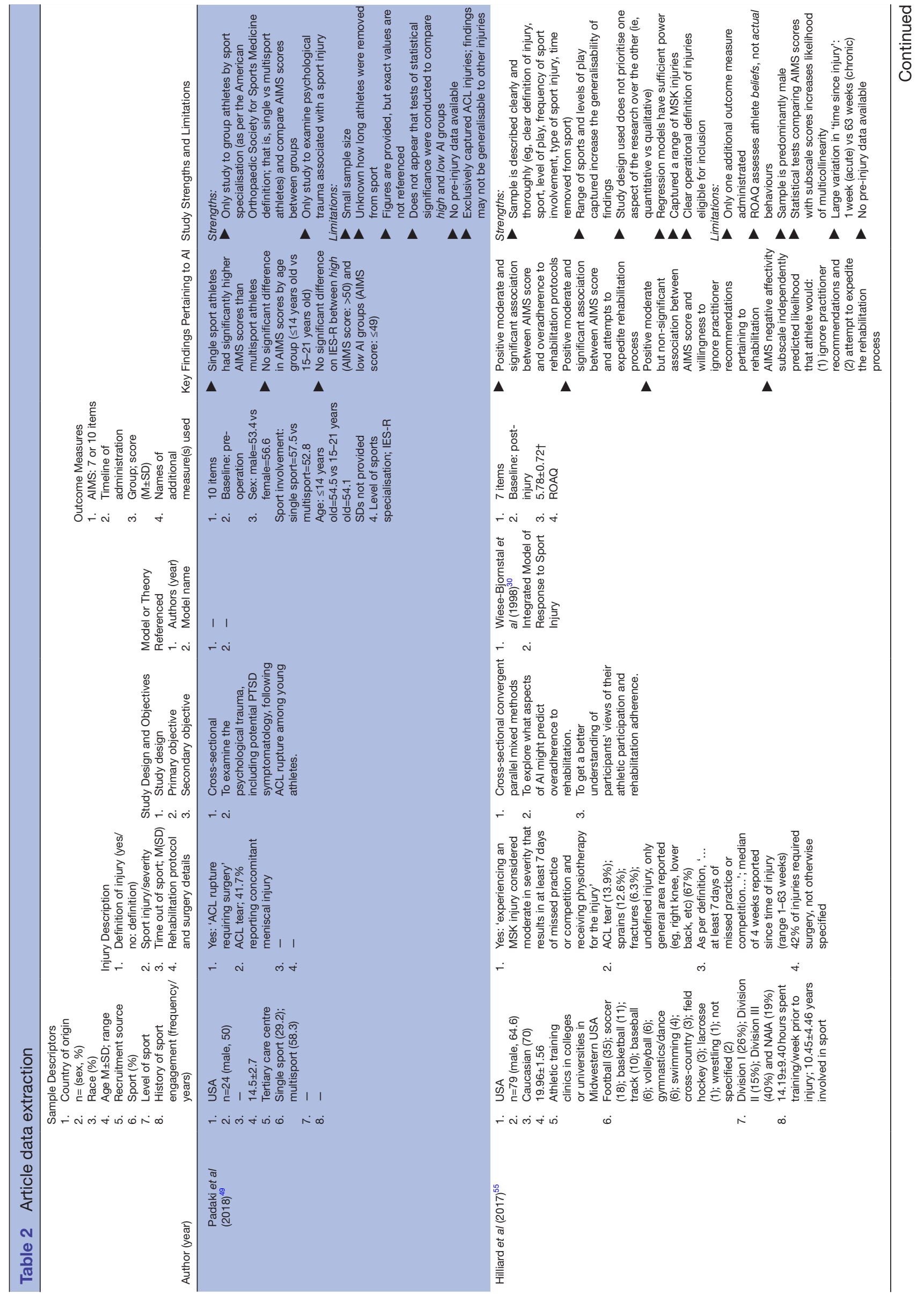




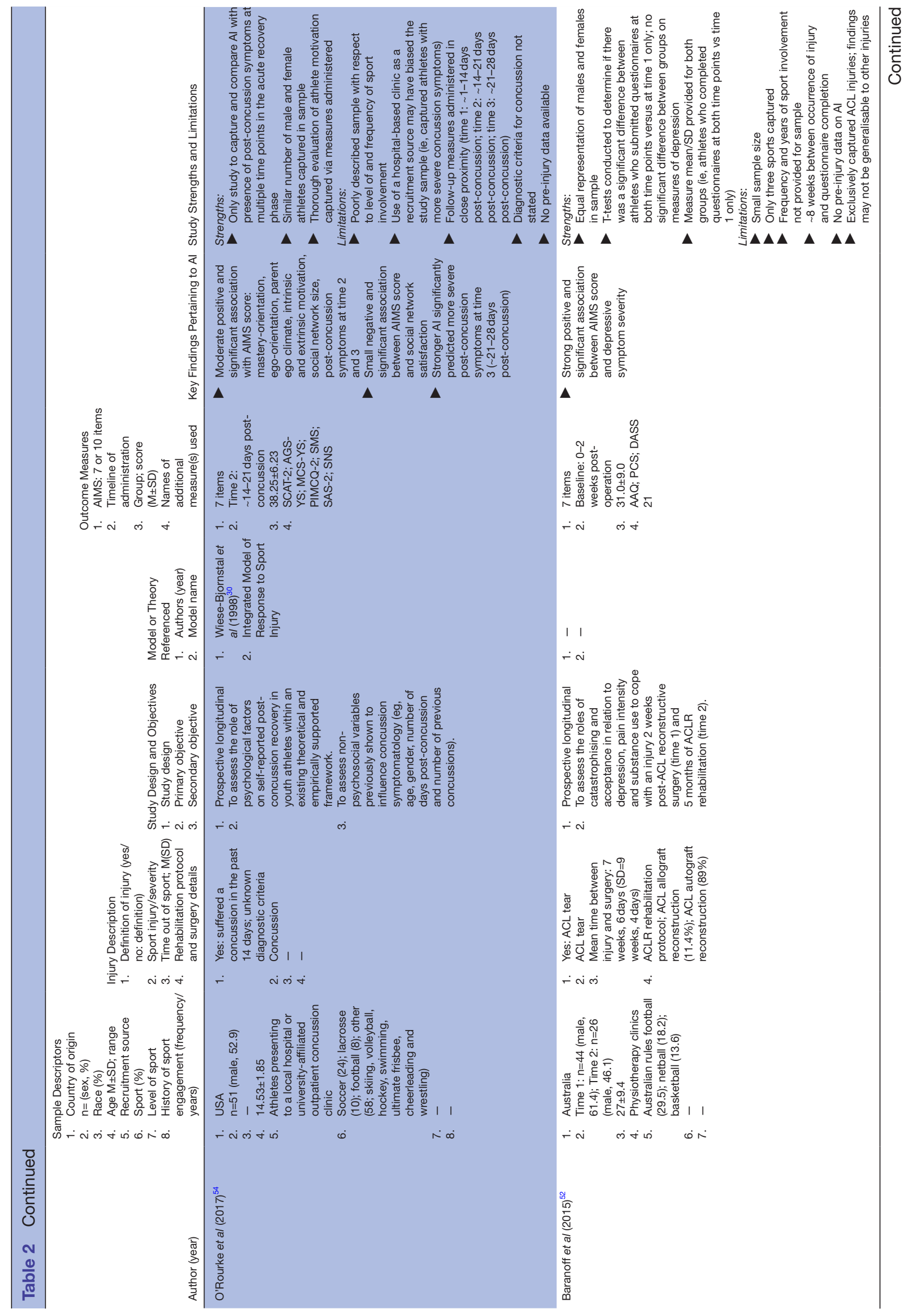




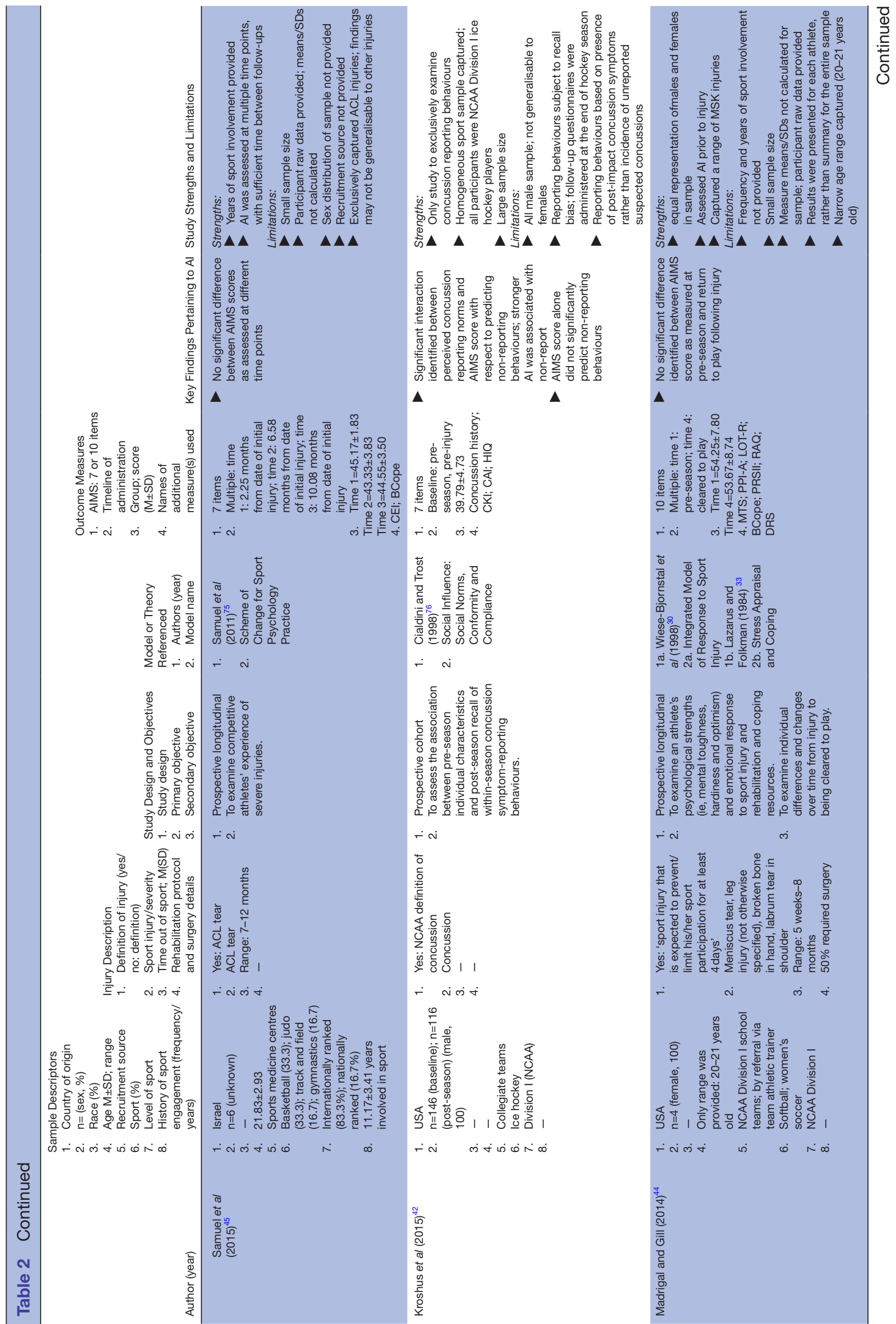




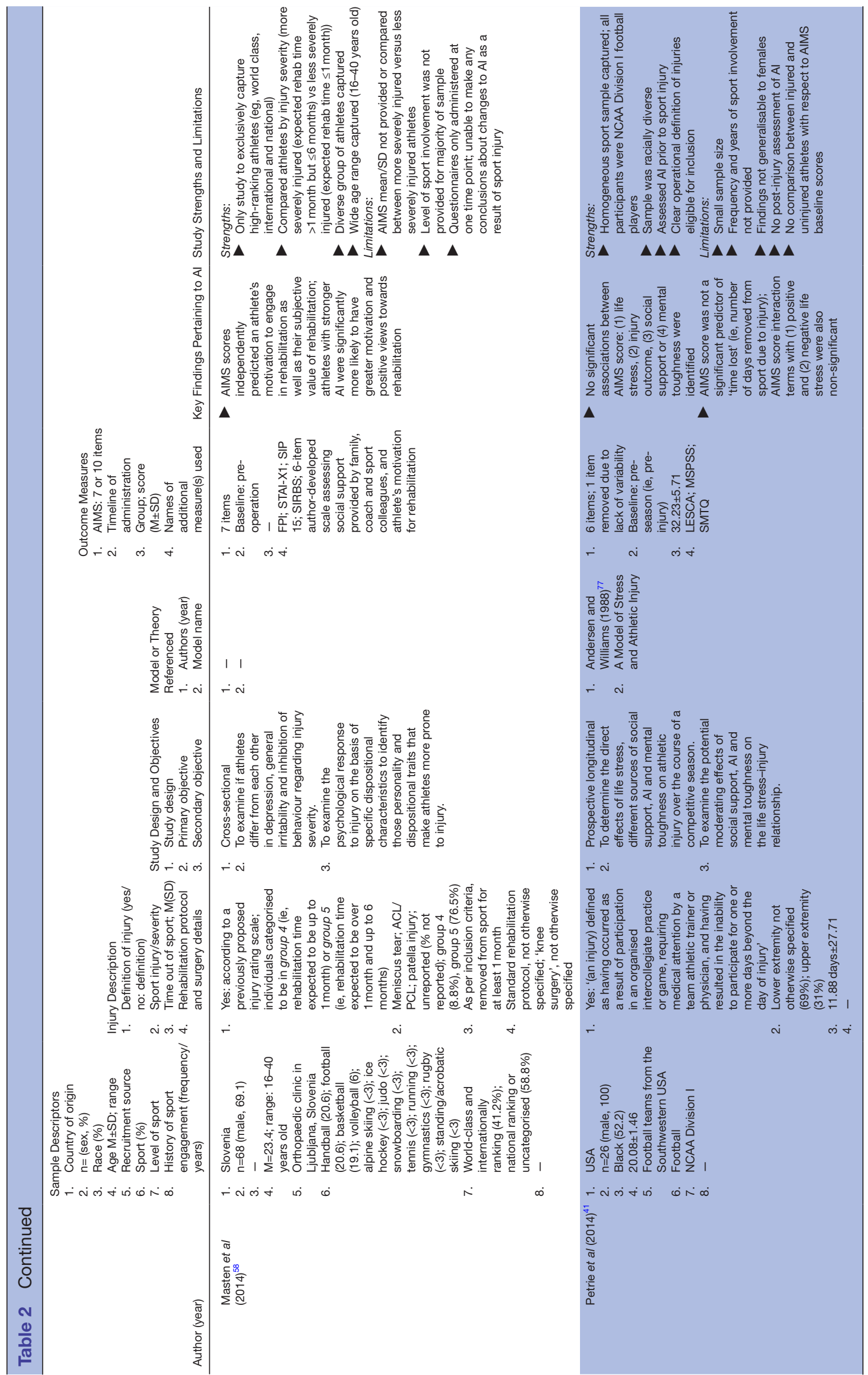




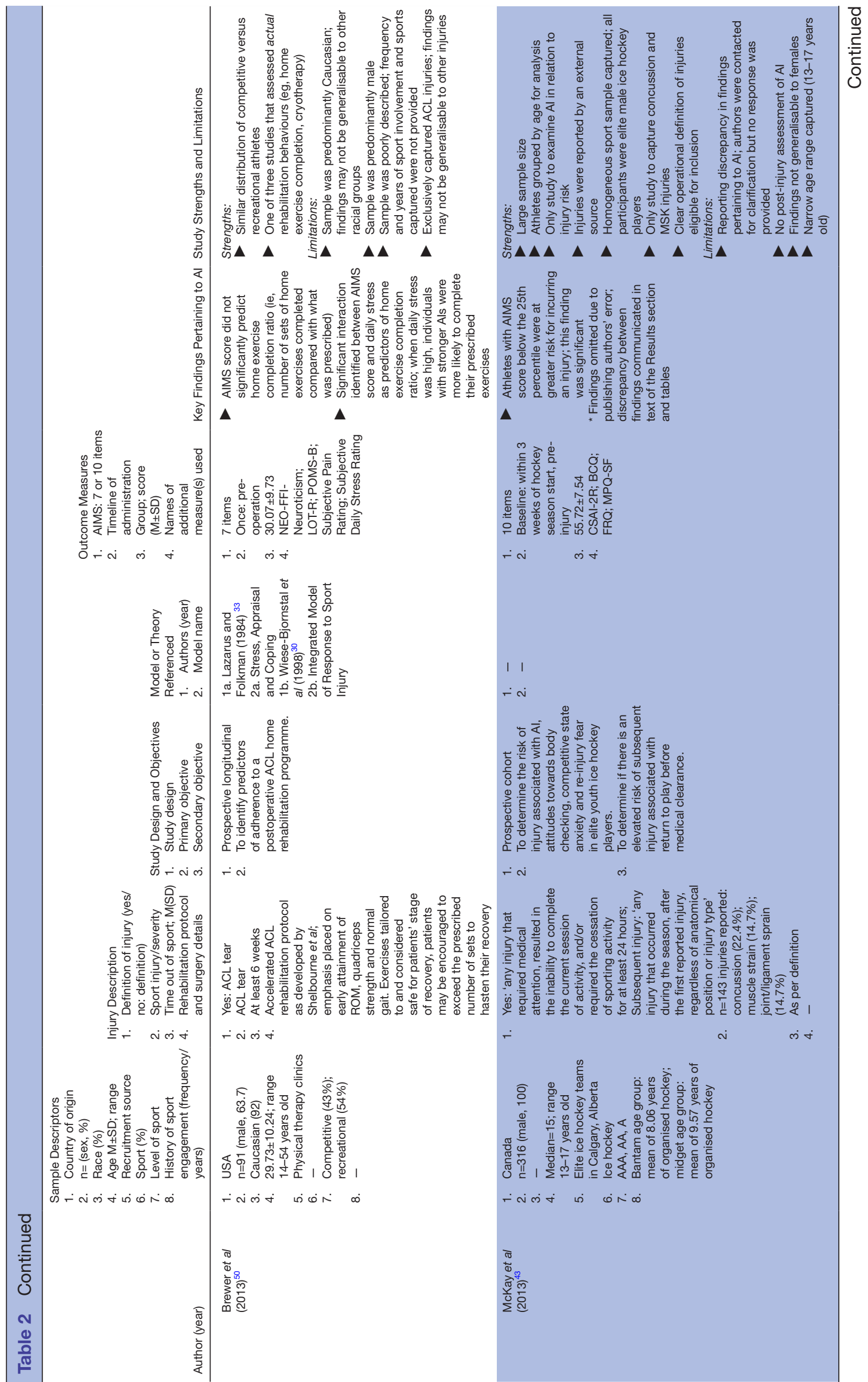




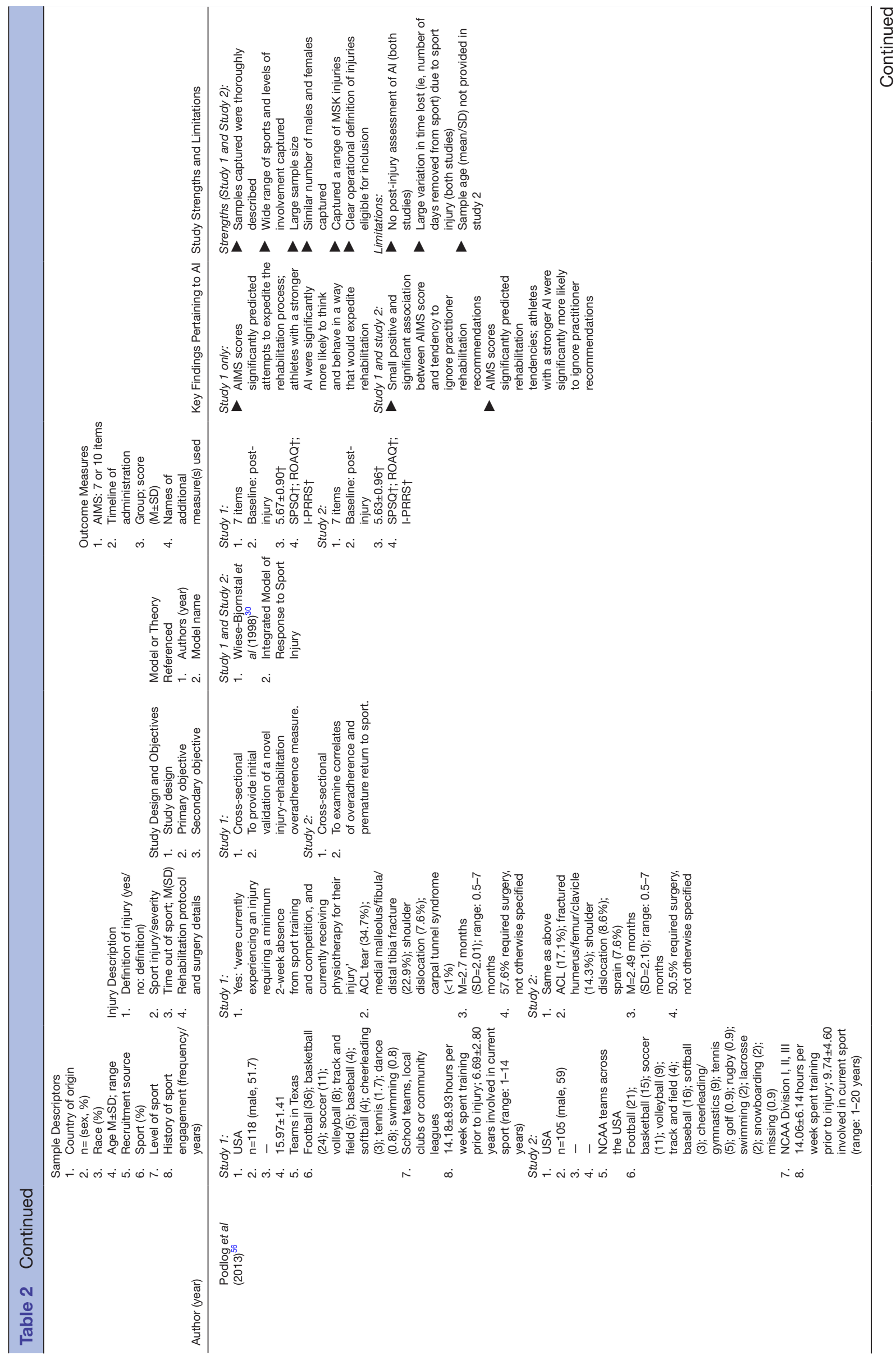




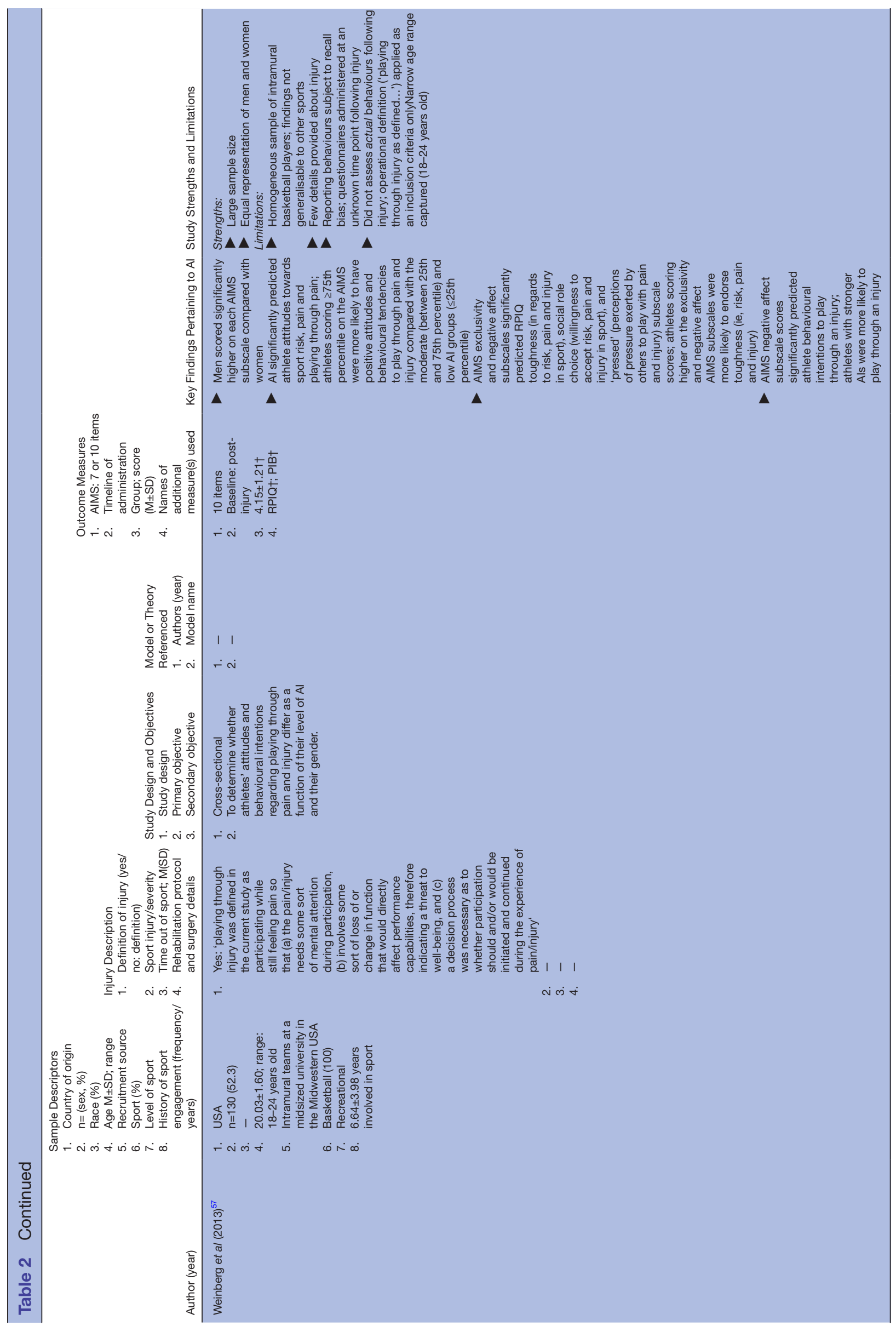




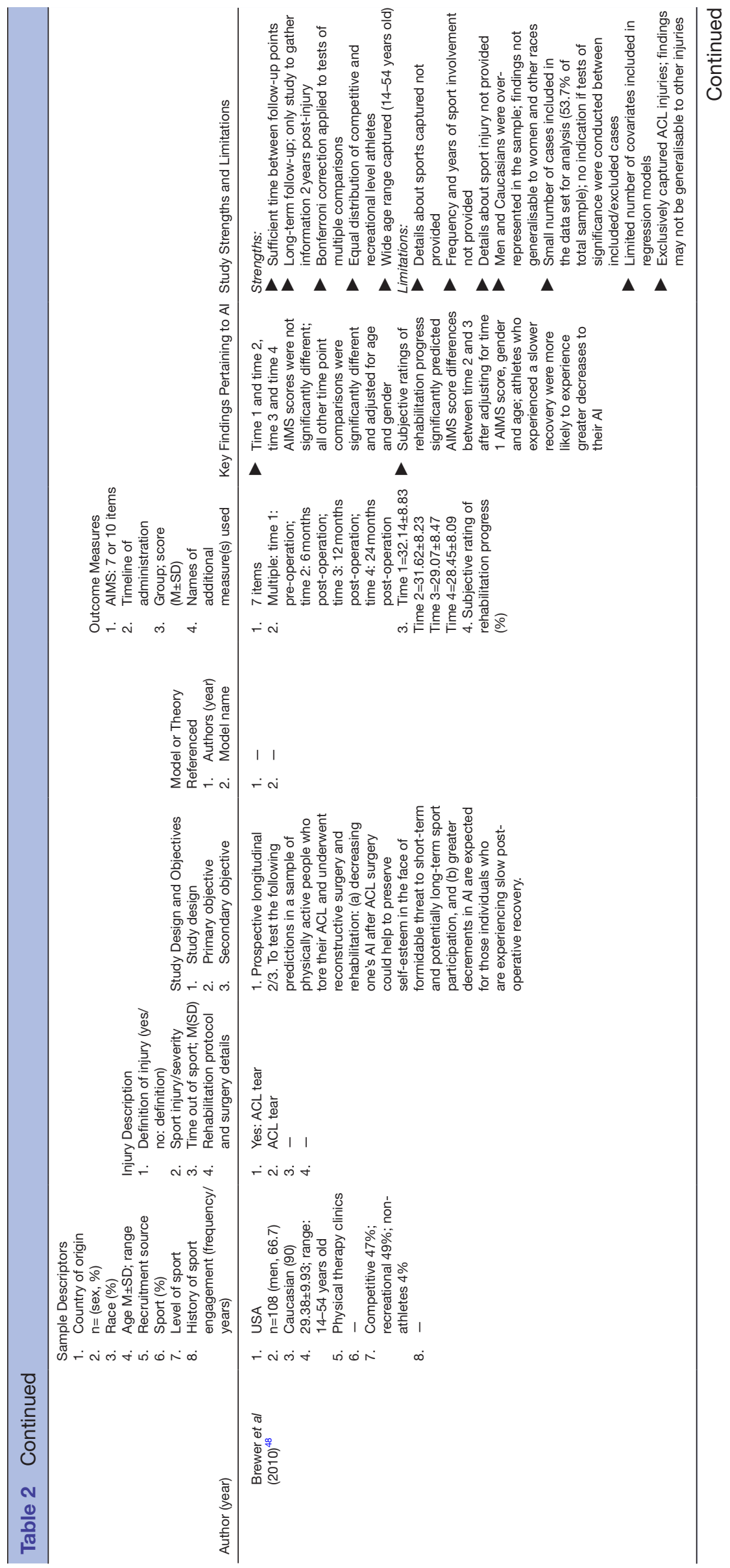




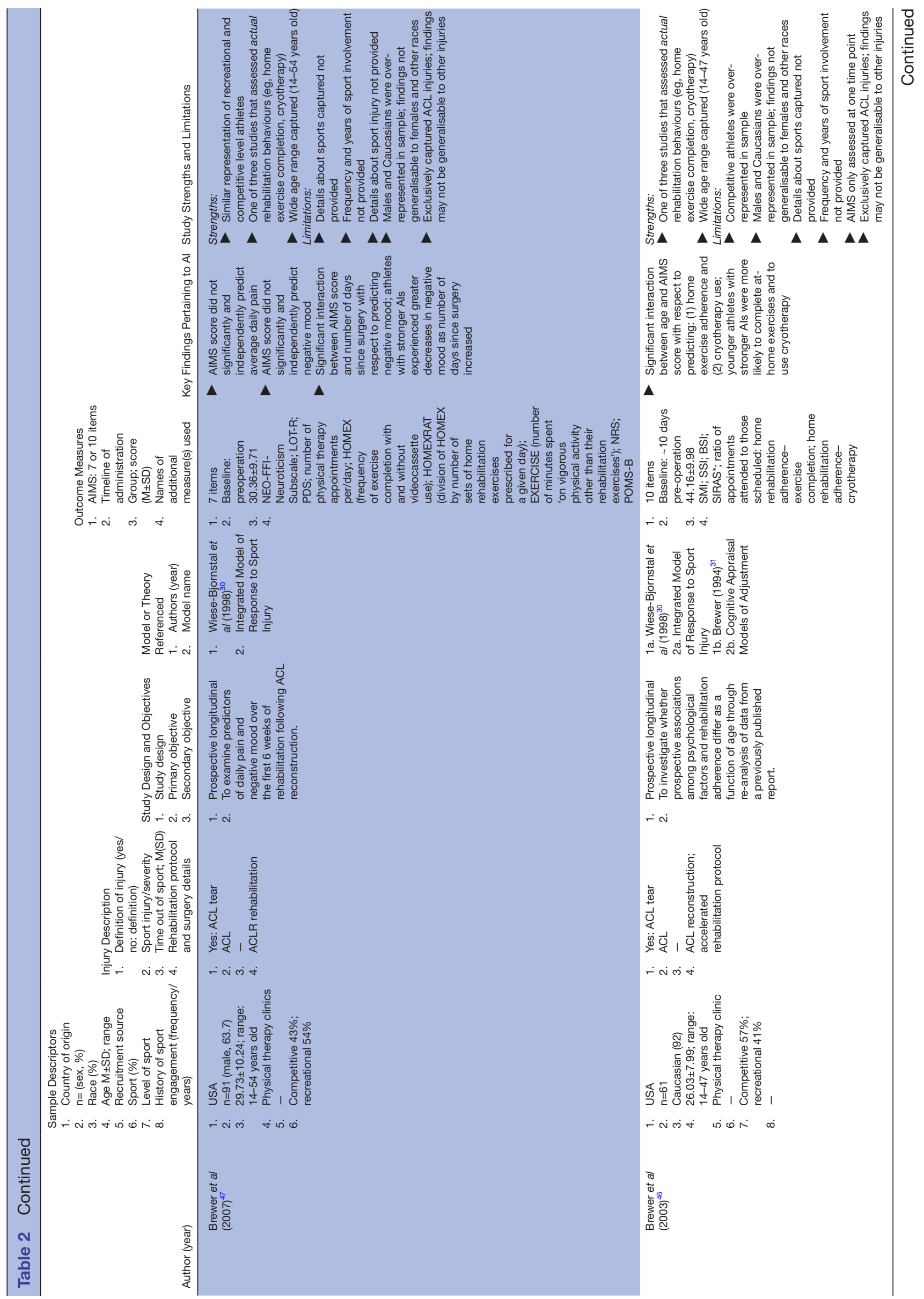




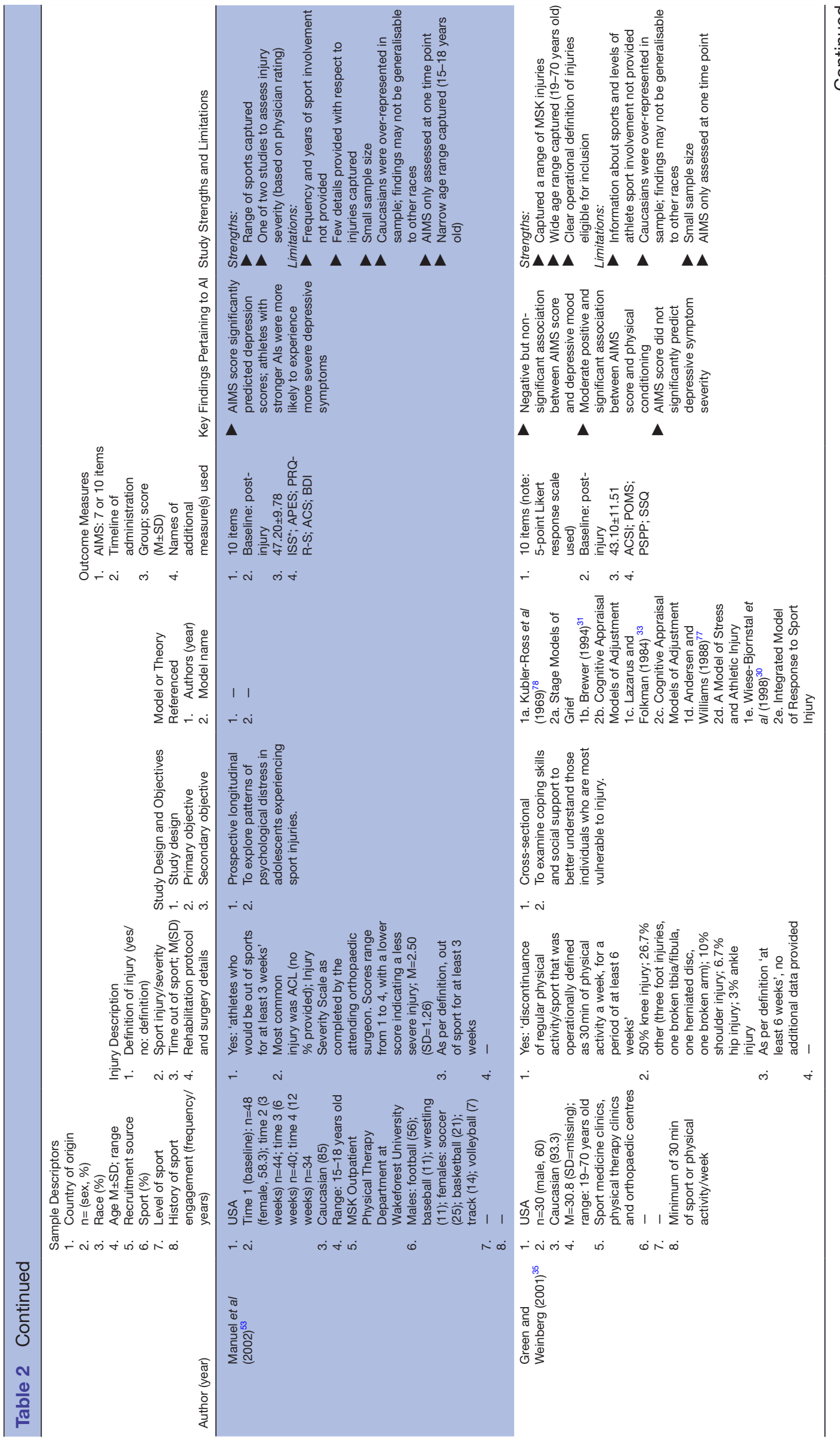




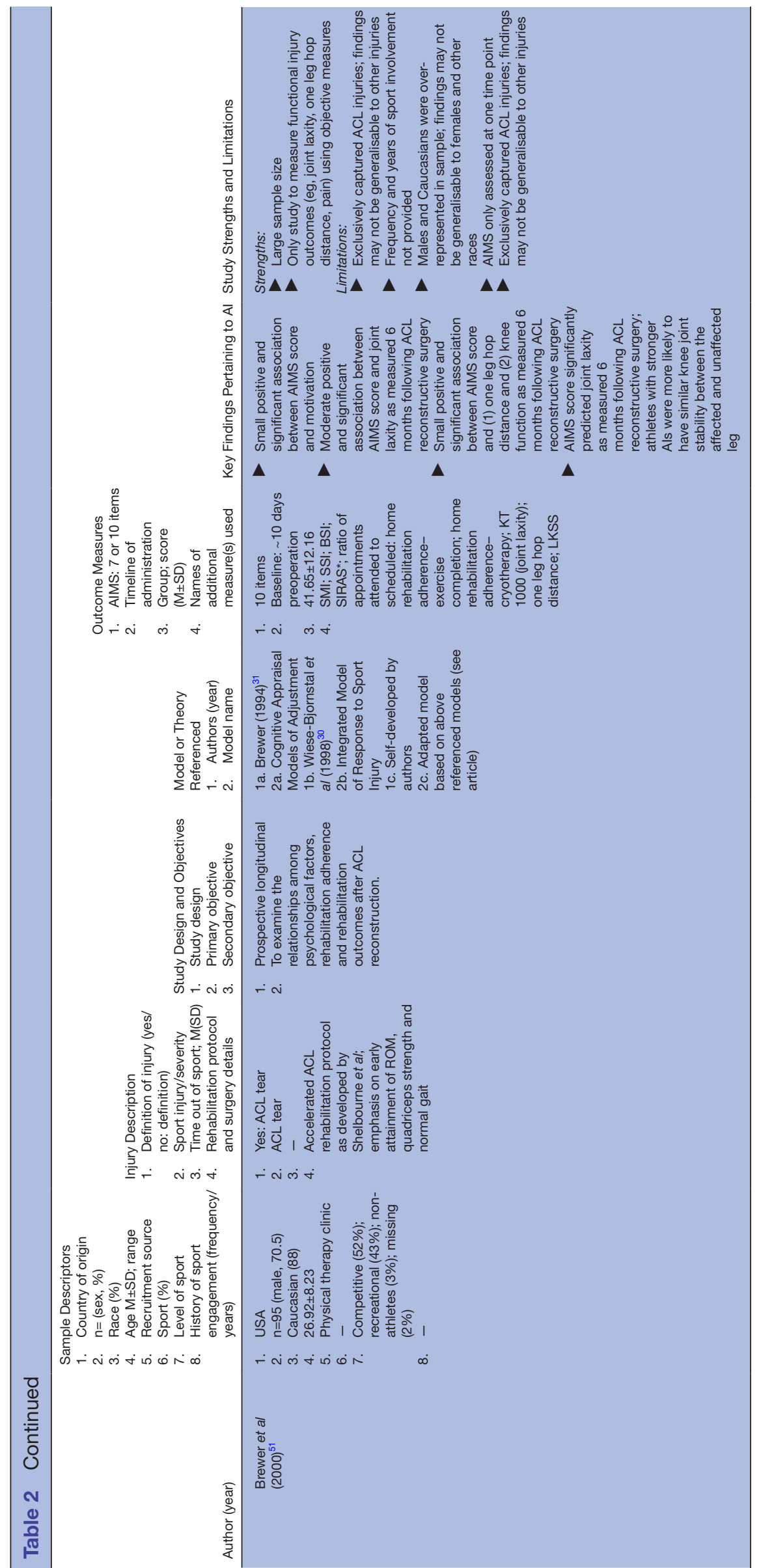




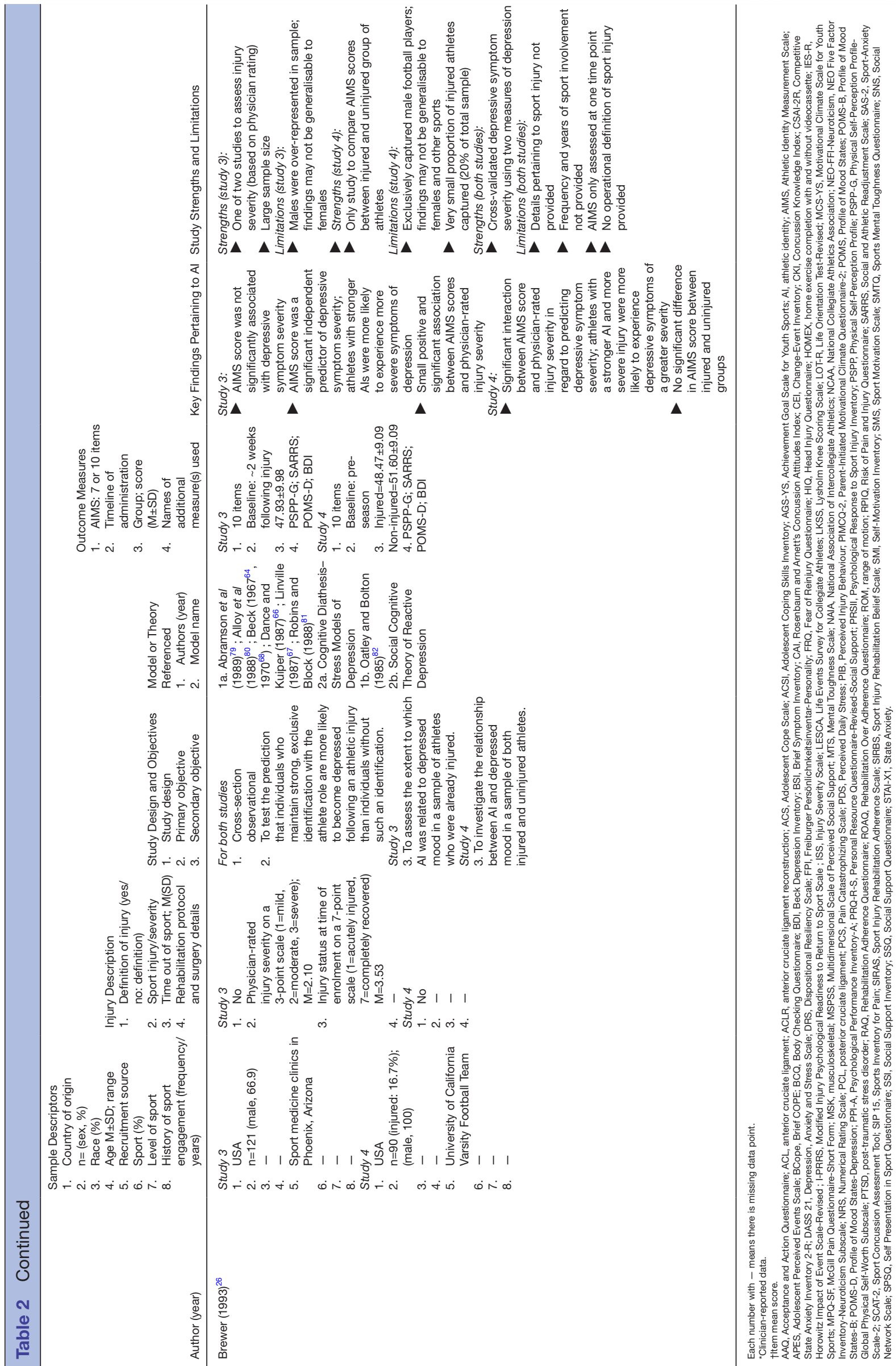


studies included both sex groups, except for three studies which included all-male samples ${ }^{41-43}$ and one which included an all-female sample. ${ }^{44}$ A total of $n=1852$ athletes were included; individual study samples ranged from a minimum of $n=6$ (45) to a maximum $n=316 .{ }^{43}$ Participants were a minimum of $13^{43}$ to a maximum of 70 years old. ${ }^{35}$ Participants were recruited from several clinical and non-clinical settings, with one study failing to specify a recruitment source ${ }^{45}$ (see table 2 , column 2 ).

Athletes were involved in a range of team and individual sports; however, several studies did not specify sport background. ${ }^{263546-51}$ Furthermore, two studies included a small proportion $\left(3 \%^{48}\right.$ and $\left.4 \%^{51}\right)$ of self-defined 'non-athletes'. Authors of this review chose to include these studies due to the small number of non-athletes ( $\mathrm{n}=7$ total) included in analyses. Samples consisted of recreational (eg, house league) and competitive athletes (eg, elite, National Collegiate Athletics Association). Several studies did not report on this metric. ${ }^{26} 354952-54$ Sport involvement (eg, frequency of and years involved in sport) was heterogeneous and reported within six studies. ${ }^{35} 434555-57$ Sport participation ranged from $30 \mathrm{~min}^{35}$ to 14.19 ( $\left.\mathrm{SD}=9.40\right)$ hours per week ${ }^{55}$ and years of sport involvement ranged from 6.64 years $(\mathrm{SD}=3.98)^{57}$ to 11.17 years $(\mathrm{SD}=4.31)^{45}$ (see table 2, column 2).

\section{Injury descriptors}

Musculoskeletal (MSK) injuries were the most common injuries cited. Nine studies reported exclusively on anterior cruciate ligament (ACL) surgical outcomes, while two ${ }^{42} 54$ exclusively examined concussion. The remaining 11 studies captured various MSK injuries. Of these 11 studies, 1 did not specify an exact injury but indicated injury to lower or upper extremities, ${ }^{41} 1$ captured both MSK injuries and concussion ${ }^{43}$ and 2 studies did not define the injuries sustained. ${ }^{2653}$ Of these two, one indicated injury severity on a scale ranging from 1 (mild) to 3 (severe) ${ }^{26}$ while the other stated that the majority of injuries were ACL tears, but did not specify the exact proportion. ${ }^{53}$ Time away from sport due to injury varied, ranging from 24 hours $^{41}{ }^{43}$ to 63 weeks. ${ }^{55}$ Ten studies did not specify a length of absence. Three studies ${ }^{41} 4357$ reported on athletes who sustained multiple injuries during the data collection period while the remaining 19 captured a first (ie, initial) injury only (see table 2, column 3).

\section{Definitions and theoretical models}

Operational definitions of injury were specified in each study except one. ${ }^{26}$ Those that captured ACL and concussions exclusively, indicated a diagnosed ACL tear or diagnosed or self-reported concussion in lieu of an operational definition. Eleven studies referenced injury models as a means of justification for study methodologies used. The most frequently cited model was the Integrated Model of Response to Sport Injury. ${ }^{30}$ Several other theories unrelated to sport injury were also referenced (see table 2, column 5).
Wiese-Bjornstal et $a l$ s injury model ${ }^{30}$ (see online supplemental appendix 3) suggests an athlete's cognitive appraisal (eg, rate of perceived recovery, cognitive coping, etc.) of the injury is a primary driver of outcome (ie, physical, behavioural and emotional). Seven studies explicitly measured cognitive appraisal via subjective rehabilitation progress, ${ }^{48}$ coping skills and strategies used, ${ }^{35} 444553$ psychological response to injury, ${ }^{44}$ readiness to return to sport $^{56}$ and rehabilitation beliefs. ${ }^{58}$ Most outcome measures sought to typify athlete personal factors. A small proportion of studies $(n=6)$ used measures that isolated situational factors (eg, sport, social and environmental), ${ }^{354146515458}$ but only assessed social support (eg, availability, quality and source).

\section{Measuring Al}

The Athletic Identity Measurement Scale (AIMS), ${ }^{59}$ 7-item or 10 -item version, was used exclusively to quantify the strength of AI (see table 2, column 6). The AIMS consists of three subscales: social identity (ie, the extent to which the individual views themselves as occupying the athlete role), exclusivity (ie, the extent to which the individual defines their self-worth based on the athlete role), and negative affectivity (ie, the extent to which the individual experiences negative emotions from undesired outcomes associated with the athlete role).$^{59}$ The findings summarised below are specific to AI. Analyses that did not consider AI were excluded from the summary. Findings were grouped into the following categories: demographic, psychosocial, behavioural, injury-specific and pain. Several studies also investigated the association between injury (as an exposure) and AI (as an outcome). These findings are presented at the end of this section.

\section{Demographics}

Findings pertaining to AI and sex were presented in two studies but were inconsistent. One study found that sex significantly predicted AIMS subscale scores, with males having significantly higher scores on each subscale (eg, social, exclusivity and negative affect) than females. ${ }^{57}$ Padaki et al also compared AIMS scores by sex (M=56.6 vs 53.4 for females and males, respectively), but this difference was not significant $(p=0.092)$. They also examined AIMS scores by sport involvement (single vs multisport athletes) and was the only study to have done so. Interestingly, single-sport athletes reported a significantly stronger AI $(\mathrm{M}=57.7)$ compared with multisport athletes $(\mathrm{M}=52.8$, $\mathrm{p}=0.043$ ). Two studies investigated AI and age, ${ }^{42} 49$ with both identifying a negative non-significant association (as age increased, AI decreased) (see table 2, column 7).

\section{Psychosocial}

Depressive symptoms were measured in six studies, but only five presented findings in relation to AIMS scores. Correlational analyses were conducted in two of the studies $^{35} 52$ while regression models were constructed in the other three. ${ }^{26453}$ Correlational analysis identified a large positive significant association between AI and 
depression scores, ${ }^{52}$ while findings from the other study identified a small negative but non-significant association. ${ }^{35}$ Beta coefficients generated from regression models illustrated a similar positive relationship between $\mathrm{AI}$ and depressive symptom severity, while also adjusting for several covariates. Two studies included AIMS scores in their models as an interaction term, one with injury severity ${ }^{26}$ and one with number of days since surgery. ${ }^{47}$ Although both models indicated that interaction terms explained a greater variance in depression scores compared to when AIMS scores were entered alone, only one interaction coefficient was significant. ${ }^{47}$ Despite evidence suggesting that athletes with stronger AIs were more likely to experience depressive symptoms following a sport-related injury, findings also indicated that they experienced greater improvements in their mood throughout the post-surgical follow-up period. ${ }^{47}$ Four studies assessed anxiety, but only one study compared anxiety symptoms (eg, sport-related performance, somatic, concentration disruption and worry) to AI. ${ }^{54}$ Despite anxiety symptoms being positively, although weakly, correlated to AI $(r=0.14$; $0.13 ; 0.21 ; 0.05$, respectively, for the type of anxiety symptoms noted in the previous sentence), findings were not significant. Another study assessed athletes for symptoms of post-traumatic stress disorder (PTSD; eg, hyperarousal, avoidance and intrusive thoughts) ${ }^{49}$ and compared PTSD scores between 'high' and 'low' AI groups prior to ACL reconstructive surgery. Group differences were not significant.

AI was significantly associated with several other, although more abstract, psychosocial constructs including sport performance traits, physical self-worth, motivation and social network size. Traits associated with sport performance such as ego-orientation (example scale item: 'The most important thing is to be the best athlete') and mastery-orientation (example scale item: 'My goal is to learn new skills and get as good as possible') were significantly associated with $\mathrm{AI}$ as represented by the moderate effect sizes observed. ${ }^{54}$ One study correlated physical self-worth (ie, perceived sport competence, perceived muscular and physical strength and conditioning) to AI and identified a positive moderate and significant association among athletes shortly after they began a rehabilitation programme. ${ }^{35}$ One study also identified a small significant association between AI and generalised motivation. ${ }^{51}$ Similarly, a moderate positive significant association was also identified between motivational climate in sport (as facilitated by parental figures) and AI. Athletes with stronger AIs also maintained greater intrinsic and extrinsic motivation towards participation in sport. ${ }^{54}$ Although social support was assessed in seven studies, only two presented findings in relation to AI. Findings indicated that the maintenance of larger social networks was moderately positively and significantly associated with AI. ${ }^{54}$ Petrie et al also examined the relationship between $\mathrm{AI}$ and social support but with respect to family, friends and significant others. Small positive but non-significant associations were identified between support provided by family, friends and AI but a negative association for significant others (see table 2, column 7).

\section{Behavioural}

Several studies investigated the relationship between AI and rehabilitation overadherence, motivation, completion of exercises and accompanying treatments (eg, cryotherapy). One study identified a small significant positive association between AI and beliefs pertaining to rehabilitation overadherence $\mathrm{e}^{55}$ and another found that stronger AIs significantly and independently predicted overadherence (ie, ignoring practitioner recommendations and attempting to expedite the rehabilitation process). ${ }^{56}$ Contrariwise, one study found that athletes with AIs $>75$ th percentile were less likely attempt to return to sport prior to medical clearance. ${ }^{43}$

Exercise completion was assessed in three studies. ${ }^{46} 5051$ Findings were inconsistent. In one study, correlational analyses identified a small positive but non-significant association between $\mathrm{AI}$ and exercise completion. ${ }^{51}$ Authors also entered AI as an interaction term in regression models. When entered with subjective stress, ${ }^{50}$ a small positive significant interaction was found. However, when entered with age in a different study, a negative significant association was identified. ${ }^{46}$ Researchers also found that younger athletes were significantly more likely to complete their exercises and cryotherapy treatments compared with older athletes. Interestingly, the opposite relationship was observed in an earlier study but findings were not significant. ${ }^{51}$

In alignment with the findings discussed above, athletes with stronger AIs were significantly more likely to place a greater value on and maintain greater motivation towards the rehabilitation process. ${ }^{58}$ Similarly, beliefs and attitudes regarding rehabilitation were also examined. ${ }^{57}$ Authors allocated athletes into subgroups based on their AIMS score ('low' $=<25$ th percentile; ' moderate' $=$ between 25 th and 75th percentile; ' $h i g h '=>75$ th percentile). Athletes in the 'high'subgroup reported significantly greater positive attitudes and tendencies to play through pain and injury than athletes in the 'low' and 'moderate' groups. When entered into a hierarchical regression model, AIMS exclusivity and negative affect subscales significantly predicted attitudes pertaining to toughness (ie, regarding risk, pain and injury in sport), social role choice (ie, willingness to accept risk, pain and injury in sport as a part of the athlete role) and 'pressed' (ie, the perception of pressure felt from others to play with pain and injury) across each subgroup. However, only the AIMS negative affect subscale was found to be a significant independent predictor of perceived injury behaviours (ie, intention to play through injury) ${ }^{57} \mathrm{~A}$ similar finding was identified by Kroshus et alin their investigation of concussion reporting behaviours. They found that athletes with stronger AIs were slightly and significantly more likely to engage in non-reporting behaviours than athletes with weaker AIs. ${ }^{42}$ Additional variance was explained when perceived 
concussion reporting norms were added to their model (see table 2, column 7).

\section{Injury-specific outcomes}

Injury severity, risk and functional outcomes were examined in several studies. Significant small effect sizes were identified between AI and physician-rated injury severity. ${ }^{26}$ Similarly, another study indicated that stronger AIs were moderately positively and significantly associated with concussion symptom severities at follow-up time points ( 14-21 daysand $\sim 21-28$ days post-concussion). When entered into a hierarchical regression model, AI significantly predicted post-concussion symptom severities $\sim 21-28$ days following injury. ${ }^{54}$ With respect to injury risk, one study found that athletes with AIMS scores $<25$ th percentile faced a greater risk compared with those $>25$ th percentile, but this difference was not significant. ${ }^{43}$ Notably, athletes with AIMS scores $>75$ th percentile were significantly more likely to have incurred a subsequent injury during the data collection period.

Only one study assessed functional recovery outcomes. Measured 6 months following ACL reconstructive surgery, AI was moderately positively and significantly associated with improved joint stability (ie, less anterior and posterior laxity in the knee joint, improved single leg hopping scores and improved subjective knee function (ie, limping, locking, instability, support, swelling, stair climbing and squatting) ). ${ }^{51}$ Findings were replicated in regression models which indicated that AI was a significant and positive independent predictor of joint stability. Psychological distress was identified as a significant negative independent predictor (see table 2, column 7).

\section{Pain}

Measures assessing subjective ratings of pain were administered in six studies, however only two analysed pain ratings in relation to AIMS scores. ${ }^{4752}$ Both studies identified small negative non-significant associations between AI and post-surgical pain ratings (see table 2, column 7).

\section{The relationship between injury as an exposure and Al as an outcome}

Of the three studies that assessed AI at multiple time points, ${ }^{44548}$ only one ${ }^{44}$ assessed AI prior to and following injury. One study found that AIMS scores decreased significantly over time (pre-surgery compared with 6 , 12 and 24 months post-surgery) after adjusting for age, sex and rehabilitation progress. ${ }^{48}$ Scores did not change significantly between pre-op and 6 months nor between 12-month and 24-month follow-up, but all other comparisons were significant. Madrigal and Gill also assessed AIMS at two time points: pre-season and return to sport. ${ }^{44}$ Small decrements in AI were observed but were nonsignificant. The final study did not conduct tests of statistical significance $^{45}$ (see table 2, columns 6 and 7).

\section{Study strengths and limitations}

The studies captured within this review have several strengths and limitations for the reader to consider.
First, the body of literature spans a 25-year period (19932018). This artefact implies that any trend or change with respect to athletes' conceptualisation of AI that may have occurred as a result of cultural progression (ie, a shift over time in group norms, the importance of the athlete role, and cultural values and ideals as they pertain to sport) is represented within the data itself. Most studies either defined a specific injury (eg, ACL tear) or provided an operational definition of sport injury, thus ensuring that inclusion criteria were applied consistently. Due to exclusive use of the AIMS, AI was conceptualised and assessed equivocally across all studies. This allows for a direct comparison of AIMS scores from one study to another. Finally, almost half of the studies included athletes from a variety of sport backgrounds, increasing the external validity of these respective studies' findings.

One of the most important limitations for readers to consider is that AI was not the primary construct of interest within the majority of the studies identified; only seven studies ${ }^{26} 4143485557$ explicitly stated that AI was a primary variable of interest within objective statements, and therefore the main variable of interest within statistical tests. Therefore, it is possible that significant relationships between AI and the assessed injury outcomes were present but went unidentified. Being that a selfreport measure was used to quantify the strength of AI, reports may have been skewed by a social desirability bias; athletes may have reported a stronger AI than their actual AI because this would be seen as desirable to other members (eg, teammates, coaches) of their social group. Another limitation with respect to the AIMS was timing and frequency of administration; 17 of 22 studies administered the AIMS following an injury and 19 studies administered the AIMS at one time point. Therefore, the existing body of literature cannot speak definitively to (1) any change over time with respect to the relationships observed between AI and the various injury outcomes observed, and (2) the relationship (if any) that exists between an injury (as an exposure) and AI (as an outcome).

Being that most studies were conducted in the USA, findings represent athletes who embody Western cultural values and attitudes towards sports and athletics. Females and athletes who identify as having a disability (eg, paraathletes) are under-represented in the literature, thus limiting the applicability of findings to these athlete populations. Studies captured a variety of MSK injuries, but few investigated AI in athletes who had sustained a sportrelated concussion. Findings may not be generalisable to this population. The majority of studies had small samples sizes $(n<100: n=15 ; n>100: n=7)$. This may have limited the type (eg, correlation vs regression modelling) and the extent (eg, number of predictor variables included in regression models) of statistical tests performed by authors. Overall, sport involvement (eg, frequency and years of involvement) as well as injury severity was poorly described within most studies. This oversight makes it difficult to gauge the dose-response relationship that 
exists between sport involvement and AI, and how this then relates to the injury outcomes observed (see table 2 , column 8).

\section{DISCUSSION}

Literature describing the relationship between AI and sport-related injury outcomes has grown steadily over the past 25 years. Importantly, 18 of 22 studies identified for inclusion in this review originated from the USA. This is important to consider when interpreting the findings presented herein given the cultural importance that different societies place on specific sports and the athlete role. ${ }^{60-62}$ The athletes described were representative of many different sports and varying levels of competition, thus increasing the external validity of this review's findings to the general athlete population. Importantly, half of the identified studies referenced a theoretical model to inform study design and methodology. However, most investigators did not discuss or interpret their findings within the context of the models originally used to position their work. The integration of novel findings as they relate to the theoretical injury outcome models referenced is necessary to progress towards predictive modelling.

Injury outcomes associated with AI were grouped into five categories. Psychosocial, behavioural and injuryrelated outcomes dominated the literature, with relatively few studies reporting results within demographic and pain-related categories. Several studies identified moderate to strong positive relationships between AI and depressive symptoms following injury. This aligns with cognitive diathesis-stress models of depression ${ }^{63-68}$ as well as previous research that has identified sport injury as a risk factor for depression in athletes. ${ }^{69-72}$ When an athlete is unable to engage in sport, as is the case when an athlete sustains an injury, depressive symptoms may occur due to ego dissonance (ie, an incongruence between who an individual believes themselves to be and their ability to fulfil their role responsibilities). As per cognitive diathesisstress models, ${ }^{67}$ athletes low in self-complexity (ie, a selfschemata consisting of a limited number of identities or significant identity overlap) are subject to a greater risk of experiencing depression following an identity disruption (eg, a sport injury) than athletes who maintain a multifaceted self-schemata (ie, maintenance of multiple identities and roles). However, this explanation fails to account for if and how the strength and importance of a given identity (eg, AI) moderates depression risk. Alternatively, depressive symptoms may manifest due to the fact that the athlete is no longer receiving the reciprocal benefits associated with role engagement. For example, studies captured in this review identified a significant positive relationship between $\mathrm{AI}$ and physical self-worth ${ }^{35}$ and general motivation. ${ }^{51}$

Behaviourally, evidence suggested that athletes with stronger identities were more likely to overadhere to prescribed rehabilitative protocols. ${ }^{556}$ This could be due to an athlete's attempt to remain in an ego syntonic state. The athlete seeks congruence between who they think they are (an athlete) and their associated role responsibilities (engaging in competition, training with teammates), so they engage in behaviours that will expedite their recovery. This behaviour may be useful, as evidence suggested that stronger AIs were associated with improved functional outcomes. ${ }^{51}$

Interestingly, pain appears to be negatively associated (although non-significantly) with AI. This might suggest that an element of mental toughness or grit accompanies stronger AIs (ie, the ability to play through and downplay pain); both of the above traits having been previously associated with sport involvement. ${ }^{12}$ It may also be the case that athletes with stronger AIs develop better coping skills to deal with injury pain and are better equipped to "push through". An alternative explanation: athletes with stronger identities opt to "push through" minor injuries and ignore minor indicators of injury (ie, pain) up to a certain threshold, which is supported by study findings. ${ }^{47}$ Additional support for this explanation is provided by studies that identified positive significant associations between AI and injury severity. ${ }^{26} 54$

As stated previously, only three studies ${ }^{45} 45$ assessed AI at multiple time points, with only one of these three having assessed AI prior to and following injury. ${ }^{44}$ Based on the available literature, there is insufficient evidence to define the relationship that exists (if any) between an injury (as an exposure) and AI (as an outcome).

\section{Strengths and limitations}

Readers should consider the following strengths and limitations of the methodology used in this review. The search strategy used to identify studies was co-constructed with the help of a University of Toronto librarian. This collaboration ensured that (1) the relevant databases for the review topic were searched, (2) the search strategy notation was applied correctly for each database, and (3) that the search terms (eg, key words, subject headings) were exhaustive and appropriate to capture studies relevant to the review topic. To prevent bias, Covidence was used to blind reviewers' decisions to accept or reject articles throughout all screening stages. Use of Covidence also ensured that all studies identified within the search were reviewed (ie, records were not missed). Finally, data extraction was conducted independently by both reviewers. This reduced the probability that study findings were transcribed erroneously within the data table and summarised incorrectly.

With respect to methodological limitations, authors did not conduct a quality and bias assessment of the identified studies. This is required and necessary prior to delineating implications for clinical care or conducting an intervention that seeks to alter AI in an attempt to improve injury outcomes. However, authors wish to remind readers that this is not the purpose of a scoping review $^{73}$ and is instead better suited to a systematic review. Researchers who wish to update this review with newly 
published literature should consider the use of a rigorous and widely accepted method of qualitative evaluation (eg, Downs and Black's Checklist for Quality Assessment ${ }^{74}$ ). The exclusion of qualitative studies, theses/dissertations and non-English articles may have resulted in the exclusion of relevant data. Finally, the search strategy used herein primarily used databases (eg, PubMed) to identify relevant studies. The incorrect labelling (eg, MeSH subject headings) of studies or studies published within journals not indexed within the databases searched were therefore missed (if any).

\section{CONCLUSIONS}

Findings from this review highlighted several significant and positive associations between AI and psychosocial (eg, depressive symptoms, performance traits, physical self-worth, motivation), behavioural (eg, rehabilitation overadherence, playing through pain and suspected injury) and injury-related (eg, function and injury severity) outcomes. Assessing AI prior to the start of a rehabilitation protocol may give both the athlete and treating clinician a road map of what to expect with respect to mindset, behaviours and recovery outcomes. Importantly, readers should consider the floor and ceiling effects of AI with respect to the relationships identified. A somewhat limited variability in mean AIMS scores does not allow for a complete representation of the AI as it relates to injury outcomes. Future studies should aim to capture athletes with a wider range of AIMS scores (ie, AI of varying strengths) as well as non-athletes who have also experienced an injury. Readers should also consider the overrepresentation of Caucasians, males, able-bodied athletes and MSK injuries identified in this review. Homogeneity in these domains limits the external validity of findings to other racial groups, females and populations with sportrelated concussion. Subsequent studies should include para-athletes as no study included in this review considered this population. Importantly, limitations associated with study design and methodology within this body of literature preclude any causal inferences from being made (ie, AI as a cause of the injury outcomes observed).

This review also highlights a large gap in knowledge with respect to the association (if any) that exists between injury (as an exposure) and AI (as an outcome). Studies must adopt prospective longitudinal designs that assess AI prior to and following the occurrence of injury in order to speak to this relationship. Additional consideration should be given to the inclusion of multiple longterm follow-up observations. As per the Wiese-Bjornstal et al injury model, ${ }^{30}$ an athlete's cognitive appraisal of the injury event is a central tenant to the outcomes observed. Despite its importance, few studies directly assessed an athlete's cognitive appraisal of their injury. Researchers may wish to inform the development of their study protocols while referencing a theoretical model. This will facilitate a more holistic understanding of the outcomes observed.
Acknowledgements The authors would like to thank Mrs Erica Nekolaichuk (University of Toronto librarian) for helping construct the search strategy used within this review. The authors would also like to thank Dr Nick Reed, Dr Sakina Rizvi, and Dr John Cairney for their critical review of and feedback on the original scoping review protocol. The authors also wish to thank the peer reviewers for their comments; their feedback has substantially improved the quality of this written work.

Contributors TR was responsible for establishing the research questions, developing and conducting the literature search, performing the title, abstract and article screening process, extracting data from eligible articles, drafting and submitting the manuscript for publication, as well as responding to peer-reviewer feedback and completing the required revisions. BP was responsible for performing the title, abstract and article screening process, extracting data from eligible articles and contributing to results and discussion sections of the manuscript draft. SK was responsible for helping establish the research questions, advising on data extraction elements and editing/revising the manuscript draft prior to submission for publication.

Funding This work was supported by a Canadian Institutes of Health Research (CIHR) Frederick Banting and Charles Best Canada Graduate Scholarship Doctoral Award (CGS-D) (fund \# 505508).

Competing interests None declared.

Patient consent for publication Not required.

Provenance and peer review Not commissioned; externally peer reviewed.

Data availability statement All data relevant to the study are included within the article or have been uploaded within supplemental files. All data extracted and summarised within this scoping review were obtained from published peerreviewed journal articles. Please refer to articles referenced.

Supplemental material This content has been supplied by the author(s). It has not been vetted by BMJ Publishing Group Limited (BMJ) and may not have been peer-reviewed. Any opinions or recommendations discussed are solely those of the author(s) and are not endorsed by BMJ. BMJ disclaims all liability and responsibility arising from any reliance placed on the content. Where the content includes any translated material, BMJ does not warrant the accuracy and reliability of the translations (including but not limited to local regulations, clinical guidelines, terminology, drug names and drug dosages), and is not responsible for any error and/or omissions arising from translation and adaptation or otherwise.

Open access This is an open access article distributed in accordance with the Creative Commons Attribution Non Commercial (CC BY-NC 4.0) license, which permits others to distribute, remix, adapt, build upon this work non-commercially, and license their derivative works on different terms, provided the original work is properly cited, appropriate credit is given, any changes made indicated, and the use is non-commercial. See: http://creativecommons.org/licenses/by-nc/4.0/.

\section{ORCID iD}

Tian Renton http://orcid.org/0000-0002-9772-0551

\section{REFERENCES}

1 Guillén F, Laborde S. Higher-Order structure of mental toughness and the analysis of latent mean differences between athletes from 34 disciplines and non-athletes. Pers Individ Dif 2014;60:30-5.

2 Laborde S, Guillén F, Mosley E. Positive personality-trait-like individual differences in athletes from individual- and team sports and in non-athletes. Psychol Sport Exerc 2016;26:9-13.

3 Kipp LE. Psychosocial aspects of youth physical activity. Pediatr Exerc Sci 2017;29:35-8.

4 Slutzky CB, Simpkins SD. The link between children's sport participation and self-esteem: Exploring the mediating role of sport self-concept. Psychol Sport Exerc 2009;10:381-9.

5 Merkel DL. Youth sport: positive and negative impact on young athletes. Open Access J Sports Med 2013;4:151-60.

6 Varkevisser RDM, van Stralen MM, Kroeze W, et al. Determinants of weight loss maintenance: a systematic review. Obes Rev 2019;20:171-211.

7 Hu MX, Turner D, Generaal E, et al. Exercise interventions for the prevention of depression: a systematic review of meta-analyses. BMC Public Health 2020;20:1255.

8 McDowell CP, Dishman RK, Gordon BR, et al. Physical activity and anxiety: a systematic review and meta-analysis of prospective cohort studies. Am J Prev Med 2019;57:545-56. 
9 Singh A, Uijtdewilligen L, Twisk JWR, et al. Physical activity and performance at school: a systematic review of the literature including a methodological quality assessment. Arch Pediatr Adolesc Med 2012:166:49-55.

10 Loprinzi PD, Frith E, Edwards MK, et al. The effects of exercise on memory function among young to middle-aged adults: systematic review and recommendations for future research. Am J Health Promot 2018;32:691-704.

11 Bueno AM, Pilgaard M, Hulme A, et al. Injury prevalence across sports: a descriptive analysis on a representative sample of the Danish population. Inj Epidemiol 2018;5:6.

12 Räisänen AM, Kokko S, Pasanen K, et al. Prevalence of adolescent physical activity-related injuries in sports, leisure time, and school: the National physical activity behaviour study for children and adolescents. BMC Musculoskelet Disord 2018;19:58.

13 Fridman L, Fraser-Thomas JL, McFaull SR, et al. Epidemiology of sports-related injuries in children and youth presenting to Canadian emergency departments from 2007-2010. BMC Sports Sci Med Rehabil 2013;5:30.

14 Centers for Disease Control and Prevention (CDC). Sports-related injuries among high school athletes--United States, 2005-06 school year. MMWR Morb Mortal Wkly Rep 2006;55:1037-40.

15 Steinbrück K. Epidemiology of sports injuries--25-year-analysis of sports orthopedic-traumatologic ambulatory care. Sportverletz Sportschaden 1999;13:38-52.

16 Yang J, Tibbetts AS, Covassin T, et al. Epidemiology of overuse and acute injuries among competitive collegiate athletes. J Athl Train 2012;47:198-204.

17 Williams JM, Andersen MB. Psychosocial antecedents of sport injury: Review and critique of the stress and injury model. J Appl Sport Psychol 1998;10:5-25.

18 Wiese-Bjornstal DM. Sport injury and College athlete health across the lifespan. Journal of Intercollegiate Sport 2009;2:64-80.

19 Meeuwisse WH. Assessing causation in sport injury: a multifactorial model. Clin J Sport Med 1994;4:166-70.

20 Brewer BW, Van Raalte J, Linder DE. Athletic identity: Hercules' muscles or Achilles heel? Int J Sport Psychol 1993;24:237-54.

21 Chen S, Snyder S, Magner M. The effects of sport participation on student-athletes' and non-athelte students' social life and identity. $J$ Issues Intercoll Athl 2010;3:176-93.

22 Horton R, Mack D. Athletic identity in marathon runners: functional focus on dysfunctional commitment. J Sport Behav 2000;23:101-19.

23 Marsh HW, Perry C, Horsely C, et al. Multidimensional Self-concepts of elite athletes: how do they differ from the general population? $J$ Sport Exerc Psychol 1995;17:70-83.

24 Petitpas. Identity Foreclosure: a unique challenge. Pers Guid J 1978;56:558-61.

25 Porat Y, Lufi D, Tenenbaum G. Psychological components contribute to select young female gymnasts. Int J Sport Psychol 1989;20:279-86.

26 Brewer BW. Self-Identity and specific vulnerability to depressed mood. J Pers 1993;61:343-64.

27 Brewer BW. Psychology of sport injury rehabiltiation. In: Tenenbaum G, Eklund R, eds. Handbook of sport psychology. Hoboken, NJ: Wiley \& Sons, 2007: 404-24.

28 Brewer BW. Injury prevention and rehabilitation. In: Brewer BW, ed. Sport psychology. Chichester. UK: Wiley-Blackwell, 2009: 83-96.

29 Appaneal R, Perna F. Biopsychosocial model of injury. In: Eklund R, Tenenbaum G, eds. Encyclopedia of sport and exercise psychology. United States: SAGE Publications, Inc, 2014: 74-6.

30 Wiese-bjornstal DM, Smith AM, Shaffer SM, et al. An integrated model of response to sport injury: psychological and sociological dynamics. J Appl Sport Psychol 1998;10:46-69.

31 Brewer BW. Review and critique of models of psychological adjustment to athletic injury. J App/ Sport Psychol 1994;6:87-100.

32 McCrea M, Broshek DK, Barth JT. Sports concussion assessment and management: future research directions. Brain Inj 2015;29:276-82.

33 Lazarus RS, Folkman S. Stress, appraisal and coping. New York, NY: Springer Publishing Company, Inc, 1984.

34 Eileen U. Coping and social support among injured athletes following surgery. J Sport Exerc Psychol 1997;19:71-90.

35 Green SL, Weinberg RS. Relationships among athletic identity, coping skills, social support, and the psychological impact of injury in recreational participants. J App/ Sport Psychol 2001;13:40-59.

36 Santi G, Pietrantoni L. Psychology of sport injury rehabilitation: a review of models and interventions. JHSE 2013;8:1029-44.

37 Clarivate analytics: endnote (version 7.7.1). Philadelphia, USA. Available: https://endnote.com

38 Innovation VH: Covidence systematic review software. Melborne, Australia. Available: https://www.covidence.org
39 Munn Z, Peters MDJ, Stern C, et al. Systematic review or scoping review? Guidance for authors when choosing between a systematic or scoping review approach. BMC Med Res Methodol 2018;18:143-7.

40 Caron JG, Bloom GA, Falcão WR, et al. An examination of concussion education programmes: a scoping review methodology. Inj Prev 2015;21:301-8.

41 Petrie TA, Deiters J, Harmison RJ. Mental toughness, social support, and athletic identity: Moderators of the life stress-injury relationship in collegiate football players. Sport Exerc Perform Psychol 2014;3:13-27.

42 Kroshus E, Kubzansky LD, Goldman RE, et al. Norms, athletic identity, and concussion symptom under-reporting among male collegiate ice hockey players: a prospective cohort study. Ann Behav Med 2015;49:95-103.

43 McKay C, Campbell T, Meeuwisse W, et al. The role of psychosocial risk factors for injury in elite youth ice hockey. Clin J Sport Med 2013;23:216-21.

44 Madrigal L, Gill DL. Psychological responses of division I female athletes throughout injury recovery: a case study approach. J Clin Sport Psychol 2014;8:276-98.

45 Samuel RD, Tenenbaum G, Mangel E, et al. Athletes' experiences of severe injuries as a career-change event. J Sport Psychol Action 2015;6:99-120.

46 Brewer BW, Cornelius AE, Van Raalte JL, et al. Age-Related differences in predictors of adherence to rehabilitation after anterior cruciate ligament reconstruction. J Athl Train 2003;38:158-62.

47 Brewer BW, Cornelius AE, Sklar JH, et al. Pain and negative mood during rehabilitation after anterior cruciate ligament reconstruction: a daily process analysis. Scand J Med Sci Sports 2007;17:520-9.

48 Brewer BW, Cornelius AE, Stephan Y. Self-protective changes in athletic identity following anterior cruciate ligament reconstruction. Psychol Sport Exerc 2010;11:1-5.

49 Padaki AS, Noticewala MS, Levine WN, et al. Prevalence of posttraumatic stress disorder symptoms among young athletes after anterior cruciate ligament rupture. Orthop J Sports Med 2018;6:2325 967118787159:232596711878715.

50 Brewer BW, Cornelius AE, Van Raalte JL, et al. Predictors of adherence to home rehabilitation exercises following anterior cruciate ligament reconstruction. Rehabil Psychol 2013;58:64-72.

51 Brewer BW, Van Raalte JL, Cornelius AE, et al. Psychological factors, rehabilitation adherence, and rehabilitation outcome after anterior cruciate ligament reconstruction. Rehabil Psychol 2000;45:20-37.

52 Baranoff J, Hanrahan SJ, Connor JP. The roles of acceptance and catastrophizing in rehabilitation following anterior cruciate ligament reconstruction. J Sci Med Sport 2015:18:250-4.

53 Manuel JC, Shilt JS, Curl WW, et al. Coping with sports injuries: an examination of the adolescent athlete. $J$ Adolesc Health 2002;31:391-3.

54 O'Rourke DJ, Smith RE, Punt S, et al. Psychosocial correlates of young athletes' self-reported concussion symptoms during the course of recovery. Sport Exerc Perform Psychol 2017;6:262-76.

55 Hilliard RC, Blom L, Hankemeier D, et al. Exploring the relationship between athletic identity and beliefs about rehabilitation overadherence in college athletes. J Sport Rehabil 2017;26:208-20.

56 Podlog L, Gao Z, Kenow L, et al. Injury rehabilitation overadherence: preliminary scale validation and relationships with athletic identity and self-presentation concerns. J Athl Train 2013;48:372-81.

57 Weinberg R, Vernau D, Horn T. Playing through pain and injury: psychosocial considerations. J Clin Sport Psychol 2013;7:41-59.

58 Masten R, Stražar K, Žilavec I. Psychological response of athletes to injury. Kinesiology 2014:46:127-34.

59 Brewer BW, Cornelius AE. Norms and factorial invariance of the athletic identity measurement scale. Academic Athletic Journal 2001;15:103-13.

60 Bradshaw L. Why do certain countries excel at certain sports? 2017. Available: https://theculturetrip.com/middle-east/articles/why-docertain-countries-excel-at-certain-sports/ [Accessed August 2020].

61 Pot N, van Hilvoorde I. Generalizing the effects of school sports: comparing the cultural contexts of school sports in the Netherlands and the USA. Sport Soc 2013;16:1164-75.

62 Andreff W. The correlation between economic underdevelopment and sport. European Sport Management Quarterly 2001;1:251-79.

63 Beck AT, Rush AJ. Cognitive approaches to depression and suicide. In: Serban G, ed. Cognitive deficits in the development of mental illness. New York: Brunner/Mazel, 1978: 235-57.

64 Beck AT. Depression: clinical, experimental and theoretical aspects. New York: Harper \& Row, 1967.

65 Abramson LY, Seligman ME, Teasdale JD. Learned helplessness in humans: critique and reformulation. J Abnorm Psychol 1978;87:49-74. 
66 Dance KA, Kuiper NA. Self-schemata, social roles, and a self-worth contingency model of depression. Motiv Emot 1987;11:251-68.

67 Linville PW. Self-complexity as a cognitive buffer against stressrelated illness and depression. J Pers Soc Psychol 1987;52:663-76.

68 Beck AT. Depression: causes and treatment. Philadelphia: University of Pennsylvania Press, 1970.

69 Appaneal RN, Levine BR, Perna FM, et al. Measuring postinjury depression among male and female competitive athletes. J Sport Exerc Psychol 2009;31:60-76.

70 Cox CE, Ross-Stewart L, Foltz BD. Investigating the prevalence and risk factors of depression symptoms among NCAA division I collegiate athletes. J Sports Sci 2017;5:14-28.

71 Mainwaring LM, Hutchison M, Bisschop SM, et al. Emotional response to sport concussion compared to ACL injury. Brain Inj 2010;24:589-97.

72 Smith AM, Scott SG, O'Fallon WM, et al. Emotional responses of athletes to injury. Mayo Clin Proc 1990;65:38-50.

73 Arksey H, O'Malley L. Scoping studies: towards a methodological framework. Int J Soc Res Methodol 2005;8:19-32.

74 Downs $\mathrm{SH}$, Black $\mathrm{N}$. The feasibility of creating a checklist for the assessment of the methodological quality both of randomised and non-randomised studies of health care interventions. J Epidemiol Community Health 1998;52:377-84

75 Samuel RD, Tenenbaum G. The role of change in athletes' careers: A scheme of change for sport psychology practice. Sport Psychol 2011;25:233-52.

76 Cialdini RB, Trost M. Social influence: social norms, conformity and compliance. In: Gilbert dT, Fiske S, Lindzey G. New York: McGrawHill, 1998.

77 Andersen MB, Williams JM. A model of stress and athletic injury: prediction and prevention. Journal of Sport and Exercise Psychology 1988;10:294-306.

78 Kubler-Ross E, Macmillan New York:. On death and dying, 1969.

79 Abramson LY, Metalsky GI, Alloy LB. Hopelessness depression: a theory-based subtype of depression. Psychol Rev 1989;96:358-72.

80 Abramson LY. Cognitive processes in depression. In: Alloy Ib. New York: Guilford Press, 1988.

81 Robins CJ, Block P, vulnerability P. Personal vulnerability, life events, and depressive symptoms: a test of a specific interactional model. $J$ Pers Soc Psychol 1988;54:847-52.

82 Oatley K, Bolton W. A social-cognitive theory of depression in reaction to life events. Psychol Rev 1985;92:372-88. 